\title{
¿Por qué la Gente Vota a la Izquierda? Clivajes, Ideología y Voto Retrospectivo en Bolivia y Uruguay en Perspectiva Comparada*
}

\section{Tomáš Došek}

Doutorando na Universidad de Salamanca (USAL) e pesquisador do Instituto de Iberoamérica da Universidad de Salamanca. Salamanca, Espanha. E-mail: tomas.dosek@usal.es

\section{INTRODUCCIÓN}

\section{$\mathrm{E}$} n los últimos quince años, diversos candidatos de izquierda han ganado elecciones y han llegado a la Presidencia de la República en América Latina. Hugo Chávez en Venezuela (1998); Ricardo Lagos en Chile (2000); Lula da Silva en Brasil (2002); Néstor Kirchner en Argentina (2003); Tabaré Vázquez en Uruguay (2004); Evo Morales en Bolivia (2005); Daniel Ortega en Nicaragua (2006); Rafael Correa en Ecuador (2006); Fernando Lugo en Paraguay (2008) y Mauricio Funes en El Salvador (2009), representan a estos nuevos gobernantes de izquierda. En varios de estos países, los mandatarios en ejercicio fueron reelegidos (Chávez, en 2006 y 2012; Correa, en 2009; Morales 2009 y 2014; Ortega, en 2011) o un nuevo candidato de la coalición gubernamental ganó la Presidencia, generando la reelección del partido y /o coalición (Fernández de Kirchner, en 2007 y 2011; Mujica, en 2009; Rousseff, en 2010). Además, en algunos países como Perú, Colombia o México, la izquierda se vio reforzada electoralmente pese a no haber triunfado en las elecciones presidenciales.

\footnotetext{
* Una versión anterior del artículo fue discutida durante una estancia de investigación en el Instituto de Ciências Sociais de la Universidade de Lisboa, Portugal. Agradezco a Iván Llamazares, Araceli Mateos Díaz, Flavia Freidenberg y Andrés Malamud por los comentarios realizados a versiones previas, así como también a dos evaluadores anónimos de DADOS - Revista de Ciências Sociais.
}

DADOS - Revista de Ciências Sociais, Rio de Janeiro, vol. 57, no-3, 2014, pp. 773 a 815. 
Tanto los análisis periodísticos como los estudios académicos (Castañeda, 2006; Castañeda y Morales, 2008; Rodríguez Garavito, Barret y Chávez, 2005; Cameron y Hershberg, 2010; Weyland, Madrid y Hunter, 2010; Levitsky y Roberts, 2011; entre otros) han intentado explicar este cambio en el cargo político más importante de los sistemas presidencialistas latinoamericanos poniendo sobre la mesa diversas explicaciones y combinando factores de corto plazo (como la evolución de la economía) y de largo plazo (como la moderación de la izquierda, la persistente inequidad o el contexto internacional). También se ha buscado identificar las similitudes y diferencias entre las propuestas y acciones de gobierno de esos políticos, con la intención de establecer si todos eran iguales o, en su caso, si había diferencias importantes entre las distintas izquierdas que habían accedido al poder de acuerdo a distintos criterios (Castañeda, 2006; Lanzaro, 2006; Paramio, 2006; Luna, 2010; Beasley-Murray, Cameron y Hersberg, 2010; Pereira da Silva, 2010; Levitsky y Roberts, 2011; entre otros).

En este debate, varios trabajos concluyeron que se podía distinguir entre (al menos) dos corrientes dentro de la izquierda. Por un lado, la izquierda contestataria (Weyland, Madrid y Hunter, 2010) o la izquierda radical (Castañeda, 2006) que gobierna en Venezuela, Bolivia, Ecuador o Nicaragua. Por otro, la moderada (Weyland, Madrid y Hunter, 2010) o socialdemócrata (Lanzaro, 2006 y 2008; Paramio, 2006) que estuvo en el poder en Chile y que preside actualmente Uruguay y Brasil. Tanto estos trabajos como los posteriores que cuestionan esta división dicotómica (Leiras, 2007; Luna, 2010; Beasley-Murray, Cameron y Hersberg, 2010; Pereira da Silva, 2010; Levitsky y Roberts, 2011; Leiras, 2007) recurrieron a distintos criterios para la clasificación: el nivel de institucionalización de la organización que respalda a los líderes de izquierda (Luna, 2010; Pereira da Silva 2010; Levitsky y Roberts, 2011), el grado de concentración de la autoridad política (Levitsky y Roberts, 2011), las restricciones endógenas y exógenas a su gobierno, la relación con los Estados Unidos (Castañeda, 2006), la crítica al neoliberalismo (Pereira da Silva, 2010), el tipo de las políticas públicas que promovía (Weyland, Madrid y Hunter, 2010) o la relación con las instituciones democráticas (Pereira da Silva, 2010; Weyland, 2013).

Este artículo busca contribuir para este debate con un análisis del comportamiento electoral, las motivaciones de voto y el tipo de vínculo entre los votantes y sus representantes. Se busca identificar los determinantes del voto en dos casos de reelección de presidentes que ejem- 
plifican las supuestas dos corrientes de izquierda: la del más radical Evo Morales, en Bolivia, y la del más moderado José Mujica, en Uruguay. Se exploran estas razones a partir del estudio del comportamiento electoral de los votantes en las elecciones presidenciales en 2009 y se analiza en qué medida se puede diferenciar entre distintas izquierdas en función de este criterio.

Por otro lado, aunque varios trabajos han intentado explicar la llegada de la izquierda al poder utilizando modelos de comportamiento electoral con datos agregados (Murillo, Oliveros y Vaishnav, 2010; Debs y Helmke, 2010; Baker y Greene, 2011; Remmer, 2012; Blanco y Grier, 2013), pocas investigaciones se han centrado en las bases de apoyo de estos gobiernos y las razones del voto a nivel individual ${ }^{1}$. Tampoco se han explorado las razones de la reelección de estos gobiernos y las lógicas a las que responde a nivel individual y el tipo de vínculo entre los votantes y los representantes ${ }^{2}$. Por lo tanto, no se han llevado a cabo análisis cuantitativos comparados con datos a nivel individual ${ }^{3}$, que permitan entender las razones de voto a los candidatos de las izquierdas y sus diferencias ${ }^{4}$.

De este modo, se realiza en este texto un análisis comparado de dos casos representativos (Gerring, 2007) o paradigmáticos de las supuestas dos izquierdas latinoamericanas, con la intención de explorar si las razones del voto por la izquierda moderada (Mujica, del Frente AmplioFA) son similares o diferentes de los que votan por la izquierda radical (Morales, del Movimiento al Socialismo - MAS) ${ }^{5}$. Varios trabajos han puesto en duda la división entre las dos izquierdas (Luna, 2010; Beasley-Murray, Cameron y Hershberg, 2010; Pereira da Silva, 2010; Levitsky y Roberts, 2011), afirmando que las diferencias son mucho más complejas y, por ende, cuestionan la utilidad de esta dicotomía. En este trabajo se espera encontrar diferencias importantes entre los dos casos aquí analizados. Los resultados se compararán con los de otros dos casos pertenecientes al giro a la izquierda, con apoyo de literatura secundaria.

El argumento principal es el siguiente: existen importantes diferencias entre las izquierdas de acuerdo a las motivaciones de voto y los vínculos con los representantes y que éstas radican en el peso de los elementos programáticos y la ideología en la decisión electoral de los votantes. A su vez, esto se deriva de las diferencias de tipo más estructural y las propias experiencias que vivieron los sistemas de partidos en los 
respectivos países. Asimismo, se sostiene que el voto retrospectivo, entendido como la evaluación del desempeño del gobierno en el poder respecto de varias cuestiones en debate, tiene un peso significativo en la decisión electoral en la mayoría de los casos de las izquierdas latinoamericanas contemporáneas.

El texto se divide en cinco partes. En primer lugar, se discuten las explicaciones ofrecidas por los trabajos cuantitativos que intentaron comprender la llegada de la izquierda al poder en América Latina. En un segundo momento, se presenta el contexto electoral de Bolivia y Uruguay, donde se realizaron elecciones presidenciales en 2009. En tercer lugar, se analiza la literatura sobre comportamiento electoral y se formulan las hipótesis, se definen las variables y se especifican los modelos. En la cuarta parte del texto, se examinan los resultados del análisis estadístico, se analizan las semejanzas y las diferencias y se discuten los demás casos latinoamericanos a partir de los estudios existentes. Finalmente, se concluye subrayando los principales hallazgos y se plantean algunos retos para futuras investigaciones.

\section{EL ASCENSO DE LA IZQUIERDA EN AMÉRICA LATINA}

Los trabajos empíricos cuantitativos que han intentado explicar la llegada de los gobiernos de izquierda al poder en América Latina (Debs y Helmke, 2010; Murillo, Oliveros y Vaishnav, 2010; Baker y Greene, 2011; Remmer, 2012; Blanco y Grier, 2013) han puesto a prueba, en su mayoría, los argumentos adelantados por los trabajos más cualitativos publicados entre 2005 y 2010 (Panizza, 2005; Castañeda, 2006; Cleary, 2006; Lanzaro, 2006; Lynch, 2007; Levitsky y Roberts, 2011). Sin embargo, la mayoría de estos análisis toman los gobiernos de izquierda como si fueran un fenómeno homogéneo, intentando encontrar los factores que explican su surgimiento $y$, a veces, el timing en los diferentes casos nacionales.

Los primeros trabajos cualitativos sugieren una serie de razones que explican el ascenso de la izquierda al poder. Uno de los primeros artículos de Castañeda (2006) sugiere que la aparición de estos gobiernos se debe a una combinación de factores del contexto internacional (caída de la Unión Soviética y fin de la Guerra Fría) y la persistente pobreza y desigualdad en la región. Esto se da en el contexto de la consolidación democrática, lo cual genera condiciones favorables a la llegada de la izquierda al poder. Un argumento similar es esbozado por Petkoff 
(2006) acerca del contexto internacional, añadiendo que los gobiernos de izquierda no son percibidos como una amenaza por parte de los EE.UU. El autor, además, plantea la importancia de los magros resultados económicos de la década de 1990 y el fracaso de las políticas del llamado Consenso de Washington.

Paramio (2006), a su vez, estima que se trata de una crisis de paradigma y sugiere un cambio de clima de opinión hacia la izquierda en la región. En la misma línea, Cleary (2006) argumenta que el resurgimiento de la izquierda se debe a una combinación de factores como la persistente inequidad, la movilización de los sectores populares, la aceptación de las elecciones como instrumento de su llegada al poder y la gradual desaparición de las limitaciones impuestas por las transiciones a la democracia. Otros autores como Rodríguez Garavito y Barrett (2005) destacan tanto los efectos negativos del neoliberalismo y la crisis de los partidos tradicionales como la importancia de los nuevos actores sociales que aparecen y reemplazan a los debilitados sindicatos y el reforzamiento de la izquierda internacional.

Trabajos posteriores han retomado algunas de las explicaciones y han agregado nuevas. Quizás la más compleja la ofrezcan Levitsky y Roberts (2011) que argumentan que el éxito de la izquierda se debe a una combinación de factores de largo plazo (la inequidad y la institucionalización de la competencia electoral) y malas condiciones macroeconómicas como resultado de las políticas neoliberales, que se profundizaron debido al boom de las materias primas y el efecto de difusión. Luna (2010) no solo destaca el desencanto con la "media década perdida" (1998-2002) y los efectos de las políticas neoliberales, sino también la crisis de los partidos tradicionales y la importancia de los nuevos líderes de izquierda y su capacidad de convocar a sectores más amplios y heterogéneos de la sociedad. Por su parte, BeasleyMuray, Olveros y Vaishnav, (2010:4) consideran el giro a la izquierda como una expresión más general del esfuerzo de refundar el actual "orden constitucional o pacto social".

Así, los argumentos de estos trabajos más cualitativos se ven reflejados en las hipótesis puestas a prueba por las investigaciones de índole más cuantitativa. Por ejemplo, Debs y Helmke sostienen que la llegada de los presidentes de izquierda se explica principalmente por los "convergentes niveles de pobreza en la región" (2010:212). Según los autores, los votantes en los países con niveles intermedios de inequidad 
aquellos tendrían mayor motivación para votar por la izquierda. Asimismo, descartan el voto económico como una explicación posible.

Murillo, Olveros y Vaishnav (2010), descartando la explicación de Debs y Helmke, confirman la importancia del voto retrospectivo. Según los autores, los votantes poseen la capacidad de accountability, y castigan a los malos resultados económicos de los gobiernos en ejercicio. Asimismo, resaltan que los votantes buscan alternativas de políticas públicas en los candidatos de izquierda. Los hallazgos de estos autores coinciden con los de Baker y Greene (2011), que ponen a prueba los dos grupos de argumentos que han encontrado en la literatura voto retrospectivo y búsqueda de políticas alternativas radicales para concluir que los votantes eligieron un alternativa moderada a las políticas anteriores. Es decir, los votantes castigaron a los gobernantes en ejercicio pero no les dieron un cheque en blanco para un giro radical respecto de las políticas neoliberales. Esto explicaría la continua implementación de diversas políticas públicas puestas en marcha durante los gobiernos neoliberales y mantenidas por varios de los gobiernos de izquierda.

El trabajo más reciente de Blanco y Grier (2013) pone a prueba los argumentos presentados en la literatura hasta el momento. Construyendo varios modelos estadísticos con la ideología de los presidentes como variable dependiente, los autores concluyen que las exportaciones de commodities y la discriminación política influyen en la presencia de los gobiernos de izquierda en América Latina. Además, encuentran que la inflación, la apertura al comercio y las crisis de los gobiernos importan según si el gobierno anterior era conservador o no.

Remmer (2012) presenta un modelo explicativo para todos los países así como también para varios países por separado teniendo como variable dependiente el nivel de aprobación presidencial. La autora halla que la satisfacción con la democracia, el voto retrospectivo económico sociotrópico y el antiamericanismo están positivamente asociados con la aprobación de los gobiernos de izquierda. También, se corren varios modelos para diferentes países por separado (Argentina, Bolivia, Brasil, Chile, Uruguay, Venezuela) con las mismas variables. Remmer (idem) aboga, siguiendo a Cardoso (2006), por la necesidad de tratar a los casos por separado, ya que distintos factores son significativos y pesan de manera diferente en los respectivos países. 
Como surge de esta breve revisión de la discusión contemporánea, los resultados de las investigaciones son frecuentemente contradictorios. Esto se puede deber tanto a la operacionalización de las variables, la diversidad de las fuentes de datos, el tratamiento estadístico y los distintos casos incluidos en los análisis, como al objetivo de explicar la llegada de la izquierda al poder como un todo, sin matices ni diferencias internas. En este sentido, el aporte de Remmer (2012) sobre la necesidad del tratamiento individual es fundamental y converge con otros trabajos que examinan un menor número de casos y ponen énfasis en las diferencias entre ellos, como el de Moncagatta y Safranoff (2013) sobre las variaciones entre las bases sociales de los gobiernos populistas (Correa frente a los Kirchner, Morales y Chávez) o el de Ratto (2013) sobre el voto económico en América Latina y la necesidad de investigar cada caso nacional por separado para determinar cómo estos últimos convergen con las tendencias regionales.

Asimismo, los estudios que han intentado explicar la llegada de los gobiernos de izquierdas al poder en América Latina han complementado los trabajos que han generado clasificaciones o tipologías de "las izquierdas" contemporáneas. En función de distintos criterios, los autores han distinguido entre dos (Castañeda, 2006; Lanzaro, 2006; Paramio, 2006), tres (Walker, 2008), cuatro (Levitsky y Roberts, 2011; Luna, 2010) y "varios" (Ramírez Gallegos, 2006), sin especificar su número.

Este artículo pretende contribuir en lo que sigue a este debate de tres maneras. Primero, se opta por una vía intermedia, analizando los casos de Mujica y Morales que han sido identificados con dos corrientes de la izquierda (Castañeda, 2006; Lanzaro, 2006; Paramio, 2006) y observando sus diferencias (y similitudes) a partir de las motivaciones de voto de los electores a partir del análisis de datos a nivel individual ${ }^{6}$. De este modo, se busca contribuir tanto a la discusión sobre las diferencias entre las izquierdas como sobre las razones de la llegada y de la permanencia de la izquierda en el poder en América Latina. Segundo, los datos provienen de los contextos de reelección en ambos países, dando un paso adelante en el análisis de la llegada de estos gobiernos al poder, al observar los vínculos entre los votantes y los representantes y al profundizar en casos nacionales, atendiendo a la necesidad subrayada por Remmer (2012) de analizar los casos por separado, sobre todo en los que supuestamente pertenecen a "diferentes" izquierdas. Tercero, los hallazgos de los casos se discuten no solo con los trabajos comparativos para toda la región sino especialmente con la literatura secunda- 
ria de otros casos nacionales pertenecientes a las diferentes izquierdas (Brasil, Argentina, Venezuela, Chile), que también experimentaron contextos de reelección.

\section{CONTEXTO ELECTORAL}

\section{Bolivia: El Ascenso de la Política Indigenista y el Triunfo Electoral de Evo Morales}

Las elecciones presidenciales en Bolivia en juicio tuvieron lugar el 6 de diciembre de 2009, y Morales ganó ya en la primera vuelta con una clara mayoría de $64,3 \%$ de votos. Su mayor competidor fue Manfred Reyes, del Plan Progreso para Bolivia - Convergencia Nacional (PPB), con el 26,5\% y en tercer lugar terminó Samuel Doria de la Unidad Nacional (UN) con el 5,7\% ${ }^{7}$. Morales ganó su segundo mandato presidencial, ya que había accedido por primera vez en 2005, también en primera vuelta, con el $53,7 \%$ de votos.

Cuando Morales se reeligió, no lo hizo como un outsider. Aunque no pertenecía a los partidos tradicionales, llegó por primera vez al Congreso en 1997 como diputado por un distrito uninominal, consecuencia de las reformas constitucionales de 1994 y de la Ley de Participación Popular (Mayorga, 2005), que buscaban mayor inclusión y participación de los sectores previamente excluidos, como los indígenas o campesinos (Córdova, 2010), a la vez que ampliaban la democracia local y la capacidad de influencia de nuevos actores sociales. En ese contexto, el MAS surgió como un "instrumento político" (idem) que aglutinaba y, al mismo tiempo, dependía de un abanico de grupos e intereses diversos.

El éxito de Morales supuso el triunfo de las reivindicaciones sindicalistas (con base en las demandas de los sectores cocaleros de la provincia del Chapare del departamento de Cochabamba) y, posteriormente, de las demandas indigenistas que habían pregonado desde la década de 1990. En los últimos años, hubo un intento de sumar el apoyo de las clases medias urbanas, de orientación de izquierda (Alpert, Centellas y Singer, 2010; Haro González, 2011). En ese contexto, Morales lideró a un conjunto de movimientos sociales cuyas demandas heterogéneas abarcaban la nacionalización de la producción gasífera, la participación efectiva de los sectores indígenas en la vida política y el descontento con los resultados de las reformas neoliberales (idem). 
El primer período presidencial de Morales estuvo marcado por varios conflictos con la oposición (Gray Molina, 2010), concentrada en los departamentos occidentales, conocidos como la región de la "Media Luna" (Santa Cruz, Beni, Pando, Tarija). Éstos incluyeron la propuesta de nacionalización de la industria del gas por medio de la Ley de Hidrocarburos, la redistribución de la tierra y la refundación del sistema político a través de una nueva Constitución que fue aprobada diez meses antes de las elecciones de 2009 y que establecía, entre otras novedades, la inclusión en el texto constitucional del carácter plurinacional del país. El conflicto por la división de poder entre el centro y los departamentos, el carácter plurinacional del Estado y su unidad y los resultados económicos fueron los temas de la campaña electoral (Alpert, Centellas y Rivas, 2010).

Pese a estas tensiones, Morales ganó las elecciones presidenciales de 2009 con un resultado aún mejor que cuatro años atrás, revalidando de manera clara su posición y dando cuenta de la debilidad de la oposición. Estos resultados se dieron en un contexto de relativo crecimiento económico, alta aprobación presidencial, la construcción exitosa de un relato basado en el cambio. Según los datos del Barómetro de las Américas (LAPOP, 2010a), Morales tuvo apoyo electoral entre las personas mayores, independientemente de su sexo y mayormente católicas. Asimismo, su base electoral estuvo en el occidente del país y logró cosechar el apoyo de casi todos los indígenas. Sus votantes eran de estratos bajos y de menor formación educativa. De casi el $40 \%$ de las personas que simpatizaban con algún partido, más del $80 \%$ simpatizaban con el MAS.

\section{Uruguay: La Consolidación del Frente Amplio}

Mujica fue electo en la segunda vuelta de las elecciones presidenciales el 29 de noviembre de 2009, alcanzado el 54,6\% de votos. En esa elección ganó al candidato del Partido Nacional, Luis Lacalle, que terminó segundo en la primera vuelta electoral con el $29,9 \%$ frente al tercero, el candidato del Partido Colorado, Pedro Bordaberry ${ }^{8}$. Mujica sucedió a Tabaré Vázquez, primer presidente de izquierda del país y líder del Frente Amplio9. La victoria de Mujica, ex Ministro de Agricultura, era esperada (Canzani, 2010), aunque no se sabía si se iba a dar directamente en la primera vuelta, como en el caso de Vázquez, o a través del balotaje. 
FA nació en 1971 y llegó por primera vez a la Presidencia de la República en 2004. En 1994, igualó a los partidos tradicionales en cantidad de votos y se pudo observar un "tripartidismo" (González, 2010). En las elecciones generales de 1999, Vázquez perdió en la segunda vuelta electoral frente a Jorge Battle (PC). El paulatino ascenso del Frente Amplio ha sido objeto de mucho interés académico. Varios autores han ofrecido explicaciones sobre su éxito electoral. Algunos trabajos han aludido al efecto demográfico (Buquet y De Armas, 2004; De Armas, 2009), a la moderación ideológica del FA (Buquet y De Armas, 2004) y su desplazamiento hacia el centro (Garcé y Yaffé, 2006), a la extensa cultura política de izquierda (Moreira, 2010) y, por último, al creciente descontento con las gestiones de los partidos tradicionales (González, 2010). El ascenso electoral y el acceso a la Presidencia en 2004 se debieron a todos esos factores, que son los que han incidido en su permanencia en el poder cinco años después.

Las elecciones se celebraron en un contexto de alta aprobación de la gestión de Vázquez, que superaba el $60 \%$ en los últimos cinco meses antes de los comicios, aunque ya se sentían algunas repercusiones de la crisis económica (Buquet y Piñeiro, 2011). Sin embargo, los resultados económicos del gobierno saliente eran positivos, destacando la gestión en materia de desempleo, la reforma tributaria, el aumento gradual del salario real y el incremento en el gasto social y de educación (Lanzaro, 2011; Buquet y Piñeiro, 2011).

Según el Barómetro de las Américas (LAPOP, 2010b), Mujica contaba con el apoyo de los sectores más jóvenes, que vivían fundamentalmente en Montevideo; que, además, eran mayoritariamente no creyentes, ateos y /o agnósticos, así como también entre las personas con mayores ingresos y de más años de formación educativa. De casi el 70\% de las personas entrevistadas que simpatizaban con algún partido, más del 70\% simpatizaban con el FA.

\section{DATOS Y MODELOS}

El trabajo explica las razones del voto a los candidatos presidenciales de izquierda en Bolivia y Uruguay. A este objetivo básico responde la especificación de la variable dependiente como dicotómica - voto por el candidato de izquierda o por algún otro ${ }^{10}$. Se busca establecer los determinantes del voto por un candidato de izquierda, y dado que en ambos casos no hubo otro candidato fuerte de izquierda en la contienda, 
se opta por emplear la regresión logística binomial, indicando que la variable dependiente puede adquirir el valor de 1 cuando el voto es a favor del candidato de izquierda y 0 , en los demás ${ }^{11}$.

La selección de las variables independientes refleja los planteamientos generales de la literatura sobre comportamiento electoral ${ }^{12}$ y las explicaciones que se han dado en la literatura sobre el "giro a la izquierda", condicionado por la disponibilidad de los ítems en la encuesta de Latin American Public Opinion Project (LAPOP). Los modelos clásicos recogen variables socioeconómicas (de largo plazo), psicológicas (de mediano plazo) y coyunturales (de corto plazo). Debido a la controversia de si la identificación (simpatía) partidista es un factor explicativo o más bien una proxy del voto ${ }^{13}$, no se incluye esta variable en los modelos ${ }^{14}$. Se construyen cuatro modelos estadísticos para indagar sobre los determinantes de voto a los dos candidatos presidenciales: primero, un modelo base solo con las variables socioeconómicas; en segundo y tercer lugar, se agregan las variables de ideología e issues programáticos y de voto retrospectivo, respectivamente; finalmente, se construye un modelo completo con dos variables adicionales: ser beneficiario de un Programa de Transferencias Condicionadas (PTC) y el nivel de confianza en los partidos.

\section{Variables Socioeconómicas}

El conjunto de las variables socioeconómicas abarca una serie de factores estructurales como sexo, edad, raza, geografía, religión, status económico de las personas, clase social, vida asociativa, nivel de ingreso y educación. Estas variables fueron incluidas en los primeros estudios de comportamiento electoral en las décadas de 1940 y 1950, en detrimento de los factores de más corto plazo, como las campañas electorales (Lazarsfeld, Berelson y Gaudet, 1944). Aquí, se incluyen como variables de control en los modelos analizados.

\section{Ideología e Issues Programáticos}

Los votantes emplean la ideología como un atajo cognitivo y una manera de reducir los costes de información para orientar su decisión al votar por un partido cuya posición ideológica le es más cercana. Se incluyen como variables independientes también dos elementos que tradicionalmente han sido identificados como los temas que distinguen a la izquierda de la derecha: el papel del Estado en la economía y la búsqueda de la igualdad en la sociedad. 
Ideología. En la literatura, existe un consenso de que ambos candidatos-gobiernos pertenecen a la izquierda (Levitsky y Roberts, 2011; Weyland, Madrid y Hunter, 2010; Alcántara Sáez, 2006). Se espera que la ubicación del votante en la escala izquierda-derecha sea significativa al momento de determinar el voto en ambos casos. Más aún, dado que el MAS, como el FA, no tiene un importante competidor en la mitad izquierda del espectro ideológico y la competencia es de carácter bipolar. Se espera que el efecto sea más significativo en Uruguay, ya que se trata de un sistema de partidos altamente institucionalizado (Mainwaring y Scully, 1995; Payne, Zovatto y Mateo Díaz, 2006), donde funcionan izquierda y derecha, y tienen altos niveles de representación programática (Mainwaring, Bejarano y Pizarro, 2008:63).

Papel del Estado. Uno de los principales ejes que polarizan la competencia partidaria en América Latina es el papel del Estado en la economía (Alcántara, 2006; Alcántara y Rivas, 2007; Kitschelt et al., 2010). Varios autores (Alcántara, 2006; Weyland, 2010) han sostenido que el objetivo de la izquierda es conseguir mayor equidad y solidaridad. Para lograr este fin, la izquierda busca potenciar el papel del Estado como responsable de una mayor redistribución de la riqueza en las sociedades.

De hecho, una de las principales propuestas de Morales para las elecciones generales, en 2005, fue la nacionalización del gas boliviano (Singer, 2007; Mayorga, 2009; Gray Molina, 2010). Se buscaba, por tanto, mayor papel del Estado, en detrimento de las empresas privadas en la gestión de los recursos naturales, y el control de su extracción, producción y gestión, de manera más general. En Uruguay, se espera que uno de los principales objetivos del gobierno de Mujica sea también mayor poder del Estado en la economía. La diferencia que se ha observado radica en que los gobiernos frenteamplistas buscaban mayor equidad y solidaridad de manera más gradual, sostenible e institucionalizada. El eje socioeconómico ha sido el más importante para la competencia partidista en Uruguay.

\section{Voto Retrospectivo Multidimensional}

Las variables del modelo de voto retrospectivo tienen que ver, por un lado, con la evaluación del desempeño del gobierno y la situación económica y, por el otro, con las políticas que se llevaron a cabo en el período de gobierno anterior. Estas últimas abarcan uno de los problemas más graves del país (LAPOP), siendo, para Bolivia, el desempleo y, 
para Uruguay, la delincuencia. Se busca evaluar hasta qué punto el voto retrospectivo puede ser multidimensional (Rennó, 2007) y no sólo una variable de tipo económica, como ha sido observado hasta ahora (Dalton y Anderson, 2011).

Este planteamiento va en línea con la propuesta sobre el voto económico en América Latina de Singer (2013), quien sostiene que incluso la importancia de los diferentes indicadores macroeconómicos (inflación, crecimiento económico) puede variar en el tiempo. Aquí, se estima que no solo los issues económicos pueden ser importantes para los votantes, sino que hay otros temas relevantes como los relacionados con la corrupción, la inseguridad o los programas sociales.

Desempeño del gobierno. En relación al voto retrospectivo, se recurre a la evaluación del desempeño del gobierno saliente. Dado que en los casos aquí abordados se trata de la reelección del gobierno anterior, en Bolivia, al mismo presidente Morales y, en Uruguay, al candidato del partido de gobierno, se espera que la buena valoración del gobierno saliente impacte de manera positiva en la decisión del voto por el candidato oficialista. Es decir, que en el juego premio-castigo, se opte por dar el premio a los buenos resultados de los dos gobiernos en cuestión.

Situación económica del país. Varios estudios que emplearon datos agregados e indicadores macroeconómicos encontraron la importancia de estos como motivación del voto (Murillo, Oliveros y Vaishnav, 2010). Para el caso boliviano de 2005, Madrid (2008) no utilizó ninguna variable económica. Sin embargo, dada la reelección de Morales y los buenos resultados económicos del país - sostenido crecimiento económico del Producto Interior Bruto y bajas tasas de desempleo (Cepal, 2010) cabe esperar una significativa y positiva relación entre la evaluación de la situación económica del país y el voto por Morales. De igual manera, el gobierno de Vázquez presentó buenos resultados socioeconómicos.

Situación económica individual. Algunos estudios han evidenciado la importancia del voto egotrópico (Queirolo, 2008). Dado los buenos resultados económicos de ambos países, es de esperar que una evaluación positiva de la situación económica personal aumente la probabilidad de voto a Mujica.

Respuesta del Gobierno frente al desempleo. Los datos LAPOP (2010a) para Bolivia indican que los ciudadanos consideran el desempleo como el 
problema más grave del país (Moreno Morales et al., 2010). Se testea, por tanto, si la evaluación de la respuesta al problema del desempleo por parte del gobierno ha sido uno de los factores que incidieron sobre el voto por Morales y, dada la reelección de Morales, se espera una relación positiva significativa.

Respuesta del Gobierno frente a la delincuencia. La delincuencia ha sido considerada por los uruguayos como el problema más grave del país (Boidi y Queirolo, 2010) y uno de los temas destacados por la oposición en la campaña electoral. Dada la reelección del candidato del Frente Amplio, se espera que la evaluación positiva de la respuesta de Vázquez en la lucha contra la delincuencia impacte de manera significativa sobre la probabilidad del voto por Mujica.

Asimismo, el modelo completo incluye dos variables que no han sido abordadas en los apartados anteriores y que están relacionadas, por un lado, con la valoración de los Programas de Transferencias Condicionadas $(\mathrm{PTC})^{15}$ que han sido implementados en los últimos 15 años en la región para atacar los problemas de pobreza y la desigualdad y, por el otro, con la confianza que tienen los ciudadanos en los partidos.

\section{Beneficiario PTC}

Varios estudios sobre Brasil han sostenido que una de las razones de la reelección de Lula da Silva en 2006 ha sido los programas sociales y, en particular, el "Bolsa Familia" (Hunter y Power, 2007). Licio, Rennó y De Castro (2009) encontraron, utilizando datos individuales de encuestas, que efectivamente hubo mayor probabilidad de voto en las elecciones de 2006 por Lula entre los beneficiarios del "Bolsa Familia". Siguiendo la misma lógica y, además, dada la tradición de clientelismo político en Bolivia (Mayorga, 2005), cabe esperar que esos beneficiarios de los programas sociales (Bono Juancito Pinto y otros) sean más propensos a votar por Morales que por la oposición.

En Uruguay, existen varios programas de ayuda social, como el denominado PANES ${ }^{16}$, que fue implementado sólo desde 2008, pero ha sido también evaluado muy positivamente por parte de los ciudadanos y, en particular, por los votantes de Mujica (Queirolo, 2010) ${ }^{17}$. Por tanto, se espera la misma relación, como en el caso de Brasil y Bolivia, aunque con menor significancia debido a la implementación más tardía de esta política pública. 


\section{Confianza en los Partidos Políticos}

En Bolivia, se ha vivido una fuerte crisis de representación de los partidos políticos, lo que ha dado cuenta de cierta decadencia de los tres partidos tradicionales que antes dominaban la vida política post-transición a la democracia (Mainwaring, Bejarano y Pizarro, 2008). También la simpatía con algunos de los partidos son menores que en Uruguay. Sin embargo, varios trabajos han dado cuenta de que líderes como Chávez, Correa o Morales lograron en cierto modo recuperar la confianza de los ciudadanos en las instituciones del sistema político ${ }^{18}$. La confianza en los partidos diferencia de manera significativa a los votantes de Morales y los demás candidatos. En el caso uruguayo, dado el arraigo de los partidos en la sociedad, de su nivel de institucionalización y de que, según los datos de LAPOP, la mayoría de los ciudadanos tiene simpatía por alguno de los partidos, es de esperar que la confianza en los mismos no sea un factor importante para la elección de Mujica.

\section{RESULTADOS: LOS DETERMINANTES DEL VOTO PARA MORALES Y MUJICA}

\section{Determinantes del Voto a Nivel Intracaso}

Los resultados arrojados por el modelo completo ofrecen valiosa información sobre el comportamiento electoral de los votantes de Morales frente al de los votantes de los candidatos opositores (Tabla 1). En primer lugar, se observa el clivaje racial, dado que los ciudadanos de raza blanca y los que se ubicaron en la categoría residual (de manera predominante los negros y mulatos) tienden a votar por la oposición. Sorprendentemente, en el modelo completo, aparece como significativo el ser "indígena" (aunque sí en el modelo socioeconómico e ideológico y de elementos programáticos). Este hallazgo difiere de lo encontrado por Madrid (2008) para las elecciones de 2005. En ese sentido, podría ser una evidencia del incipiente conflicto dentro de la heterogénea coalición que compone el movimiento que respalda a Morales, más concretamente, con algunos de los sectores indígenas ${ }^{19}$. No obstante, la cuestión étnica sigue presente y confirma los planteamientos de Albó (2007), Romero Ballivián (2007) o Mayorga (2010) sobre la importancia de este tema. 


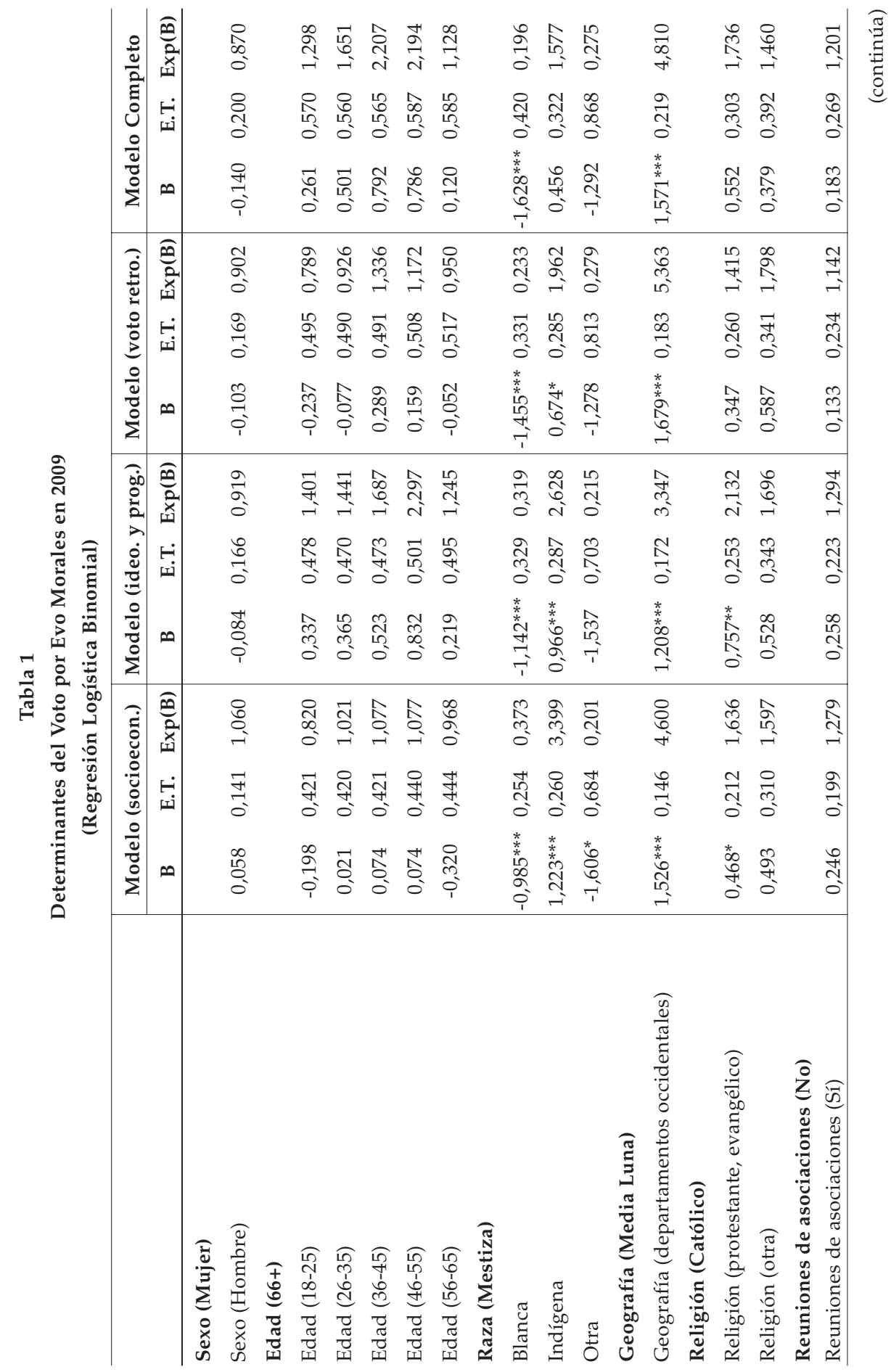


¿Por qué la Gente Vota a la Izquierda?

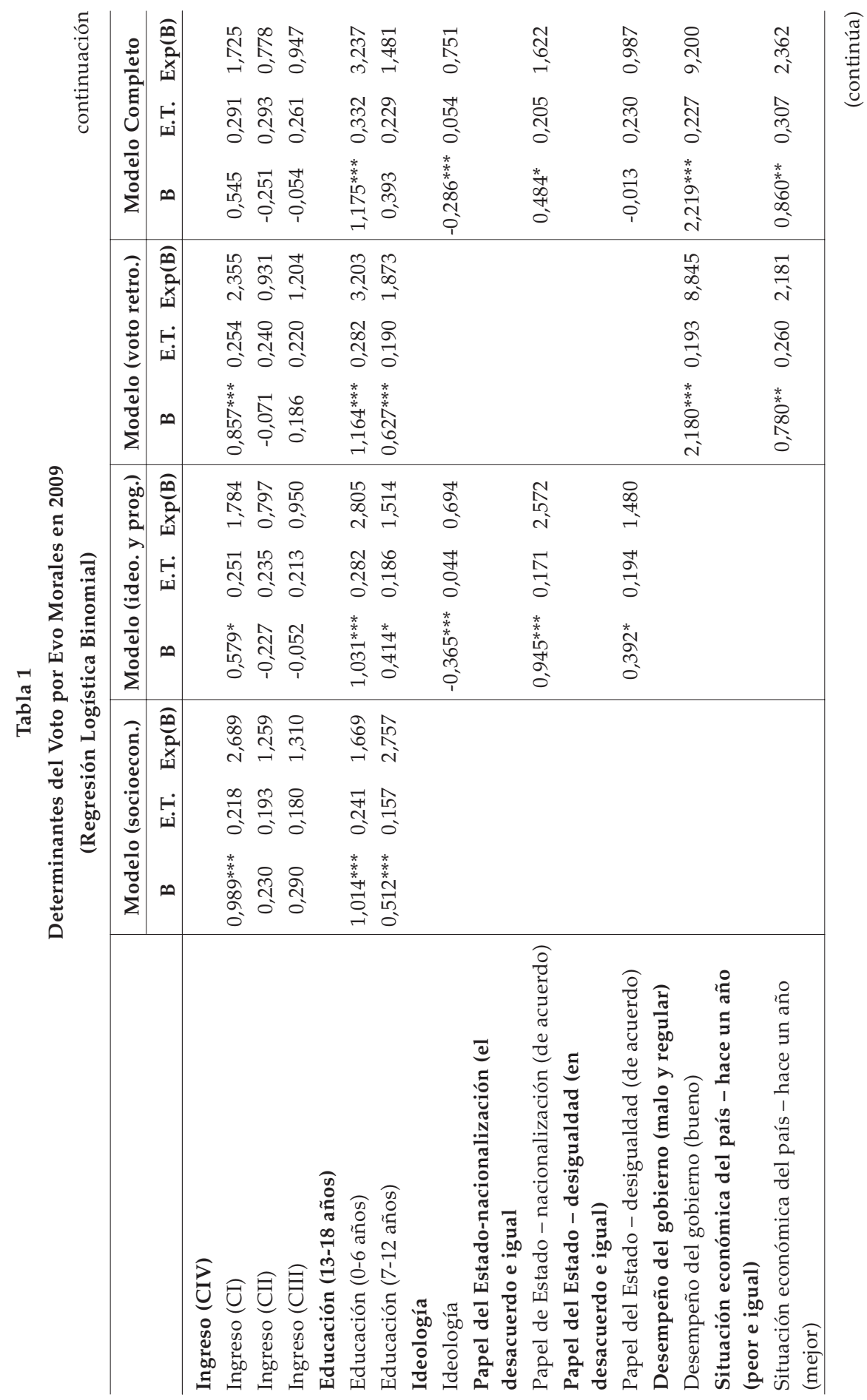

DADOS - Revista de Ciências Sociais, Rio de Janeiro, vol. 57, n 3, 2014 


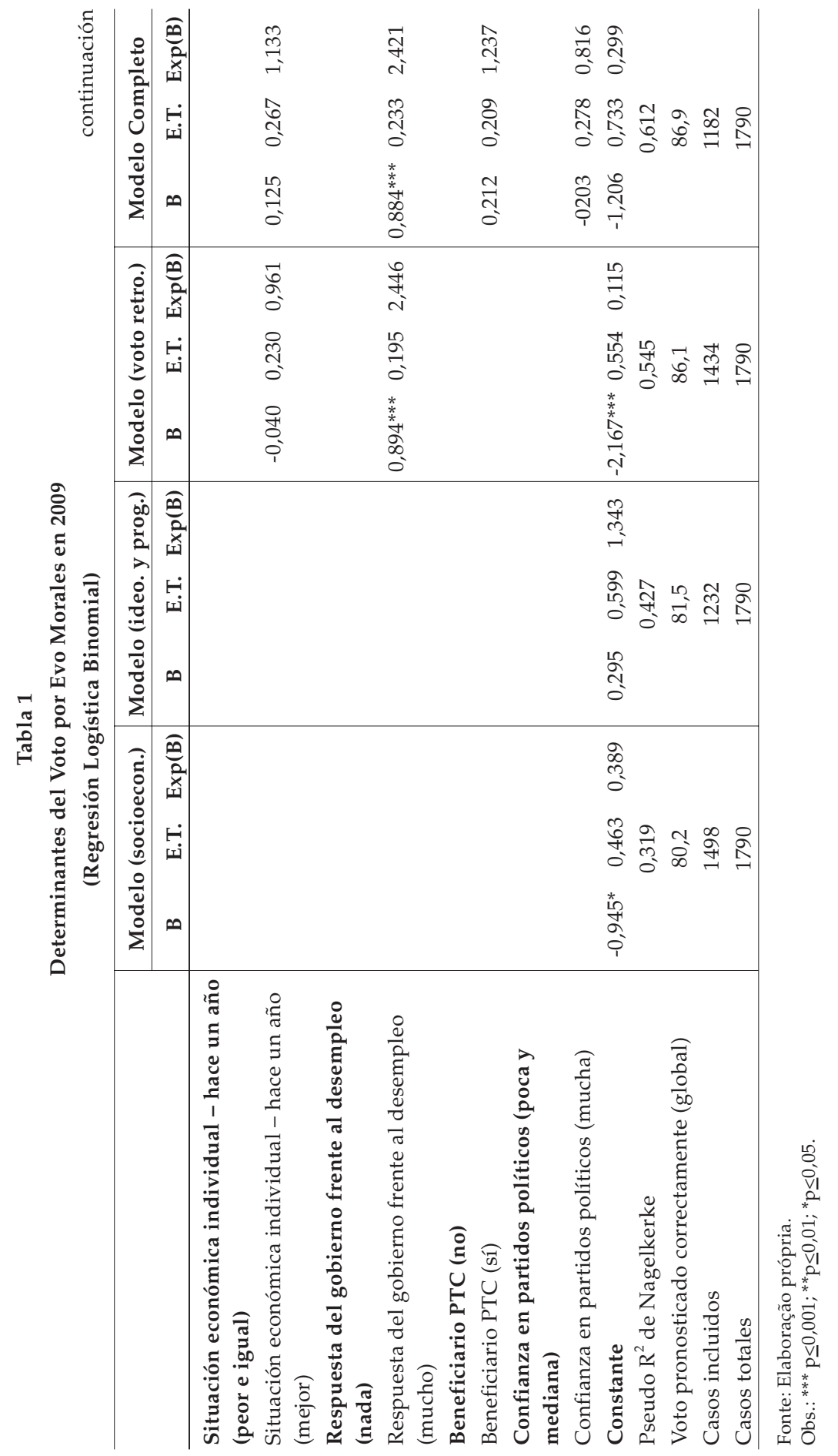


El conflicto regional permanece, pese a los avances electorales de Morales hacia el Oriente y la tensión entre los departamentos orientales y la Media Luna (Albó, 2007; Madrid, 2008; Alpert, Centellas y Rivas, 2010; Mayorga, 2010; Haro González, 2011). Éste se originó en la emancipación de los departamentos tras la celebración de las primeras elecciones subnacionales de manera concurrente con las elecciones nacionales en 2005. Desde ese momento, los departamentos orientales se convirtieron en "los representantes de los partidos tradicionales" (Haro González, 2011:246), la base de apoyo de Reyes, y la tensión se ha reforzado fundamentalmente debido al conflicto por las competencias entre el nivel nacional y el nivel subnacional (Gray Molina, 2010).

Respecto al nivel de ingreso y educación, la primera variable distingue poco entre los electores de Morales y sus competidores. Esto corroboraría la idea planteada por varios especialistas (Alpert et al., 2010; Haro González, 2011; Vargas del Carpio Ribert, 2011) de que Morales ha buscado el apoyo más transversal, con énfasis en las clases medias (sobre todo en las localidades urbanas), durante el primer período de su gobierno. El análisis de la variable ingreso, por cuartiles, indica que no hubo diferencia entre Morales y los candidatos de derecha en este aspecto, pese al creciente apoyo de las clases medias al primero.

En relación a la ideología, ésta logra dividir a los votantes bolivianos, siendo los de izquierda los más propensos a votar por Morales. Esto da cuenta de que las categorías ideológicas de izquierda y derecha, por un lado, son útiles en Bolivia y, por el otro, que sirven como predictores de la votación. Sin embargo, es probable que esto se deba a que Morales era el único candidato importante de izquierda, sin otra clara alternativa. Asimismo, este resultado difiere, una vez más, de lo expuesto por Madrid (2008) que no encontró que la ideología fuera significativa.

Contrariamente a lo esperado, el modelo completo no evidencia como estadísticamente significativo la nacionalización de bienes y servicios (papel del Estado en la economía) y la cuestión de la desigualdad. Esto, por un lado, podría apuntar a que se trata de temas transversales que no logran diferenciar a los electores o, por el otro, de que los bolivianos no consideran a estos temas importantes frente a la evaluación de los resultados del gobierno saliente. Respecto de la elección de 2005, Madrid (2008) encontró muy significativa la cuestión de la nacionalización del gas. Los resultados de este trabajo no encuentran una fuerte relación entre nacionalización, operacionalizada a partir de la pregun- 
ta sobre si el Estado debería ser el dueño de las grandes empresas, y el voto por Morales. Esto puede deberse a que las nacionalizaciones realizadas entre 2005-2009 (sectores de la construcción, la energía, las telecomunicaciones, la minería) no fueron percibidas como tan importantes y que el símbolo era la industria del gas.

La idea de que el Estado debería buscar la igualdad entre todos los ciudadanos, un tema importante de la izquierda (Levitsky y Roberts, 2011), tampoco logró distinguir entre los votantes de Morales y los candidatos de derecha. Esto ocurre a pesar de que Morales ha ejecutado varios programas de apoyo a los sectores más vulnerables (Bono Juancito Pinto, Bono Madre Niño-Niña Juana Azurduy, Renta Dignidad) en búsqueda de la eliminación de las diferencias entre los sectores sociales. Esto podría indicar que se trata de un tema transversal que no divide a la competencia partidista.

Si tenemos en cuenta las tasas de aprobación ciudadana, los resultados macroeconómicos relativamente buenos y la ausencia de una candidatura fuerte de oposición nacional, los resultados empíricos son consistentes con las hipótesis de la importancia de la evaluación del desempeño del gobierno saliente, de la evolución de la situación económica del país y también de la percepción del esfuerzo hecho por el gobierno de Morales frente al desempleo. Por el contrario, no se muestra estadísticamente significativa la evaluación de la situación económica personal (voto egotrópico). Los resultados concuerdan en este sentido con varios trabajos previos que sostienen que el voto en América Latina es más bien retrospectivo (Remmer, 1991; Lora y Olivera, 2005; Murillo, Oliveros y Vaishnav, 2010; Remmer, 2012; Ratto, 2013; Singer y Carlin, 2013).

Los resultados del modelo completo para Uruguay dan cuenta de dos clivajes estructurales (Tabla 2). En primer lugar, se mantiene la división del voto entre la capital y otras ciudades grandes del país frente a las poblaciones más pequeñas y de las áreas rurales. Esta variable sigue siendo muy significativa a nivel individual, pese a que varios autores han sostenido que el voto para el Frente Amplio se ha nacionalizado (Lanzaro, 2004), que su regionalización ha disminuido desde 2004 (Moreira, 2010) o que ha habido cierta homogeneización espacial del comportamiento del electorado (Buquet y De Armas, 2004). 
¿Por qué la Gente Vota a la Izquierda?

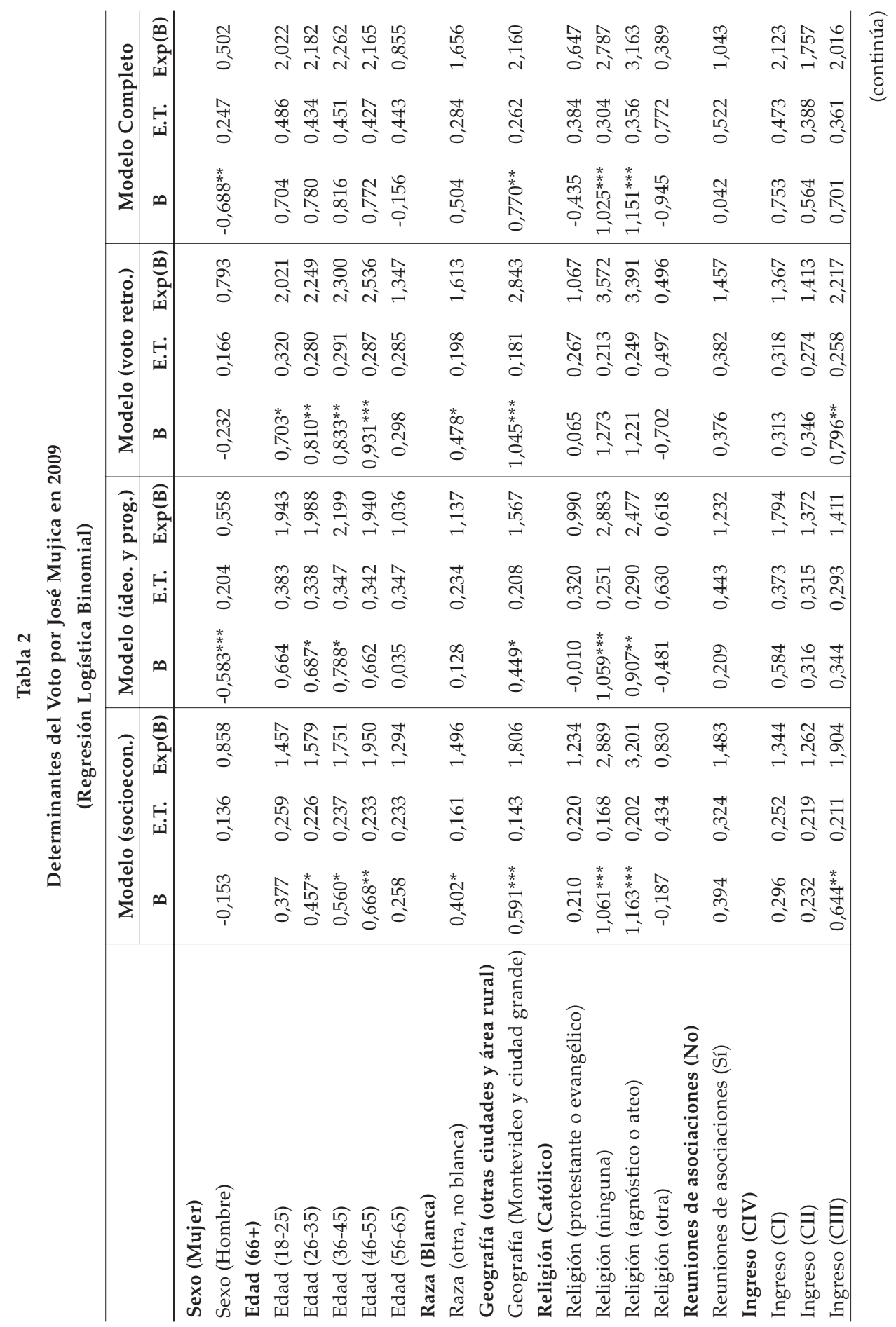

DADOS - Revista de Ciências Sociais, Rio de Janeiro, vol. 57, nํㅡ, 2014 


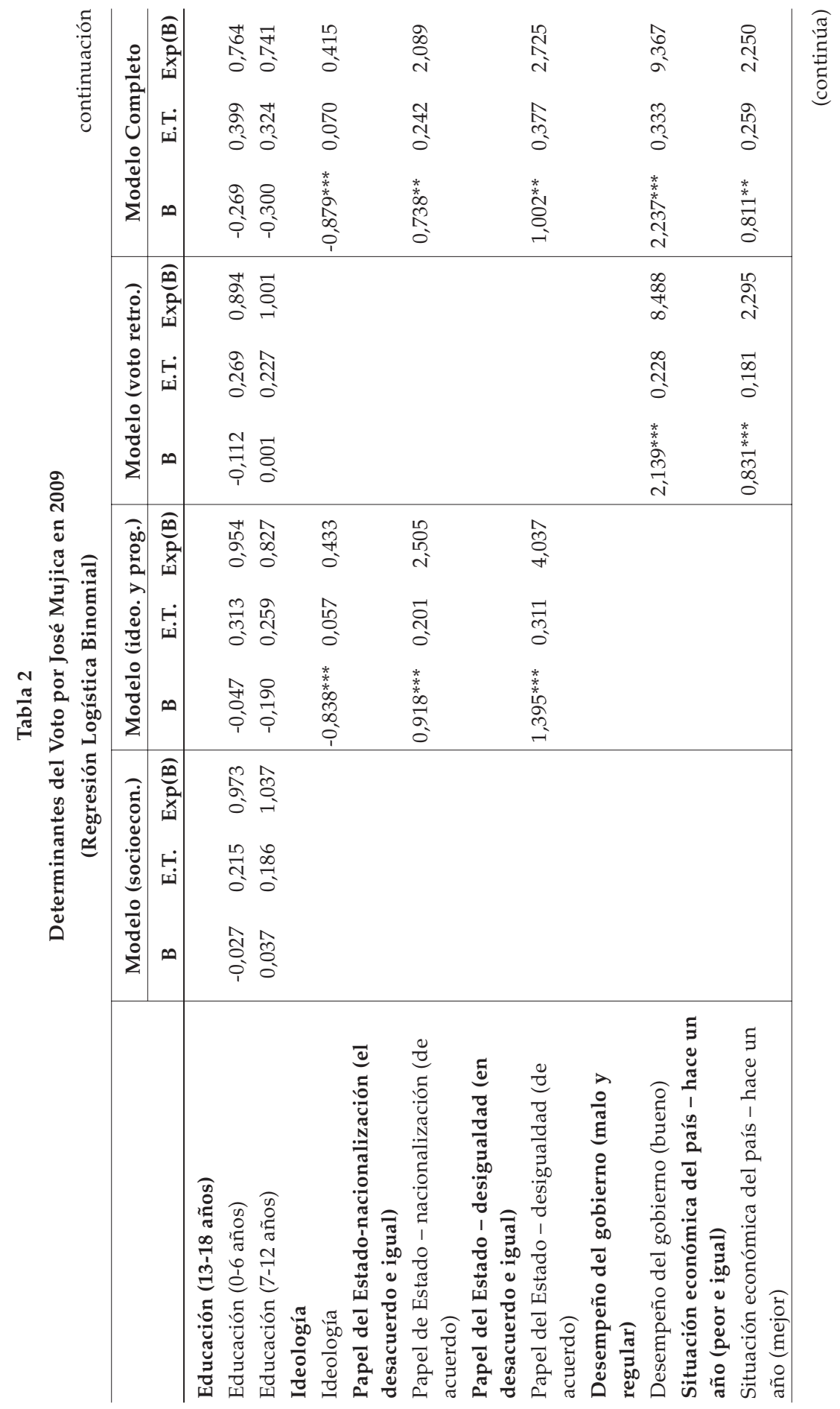


¿Por qué la Gente Vota a la Izquierda?

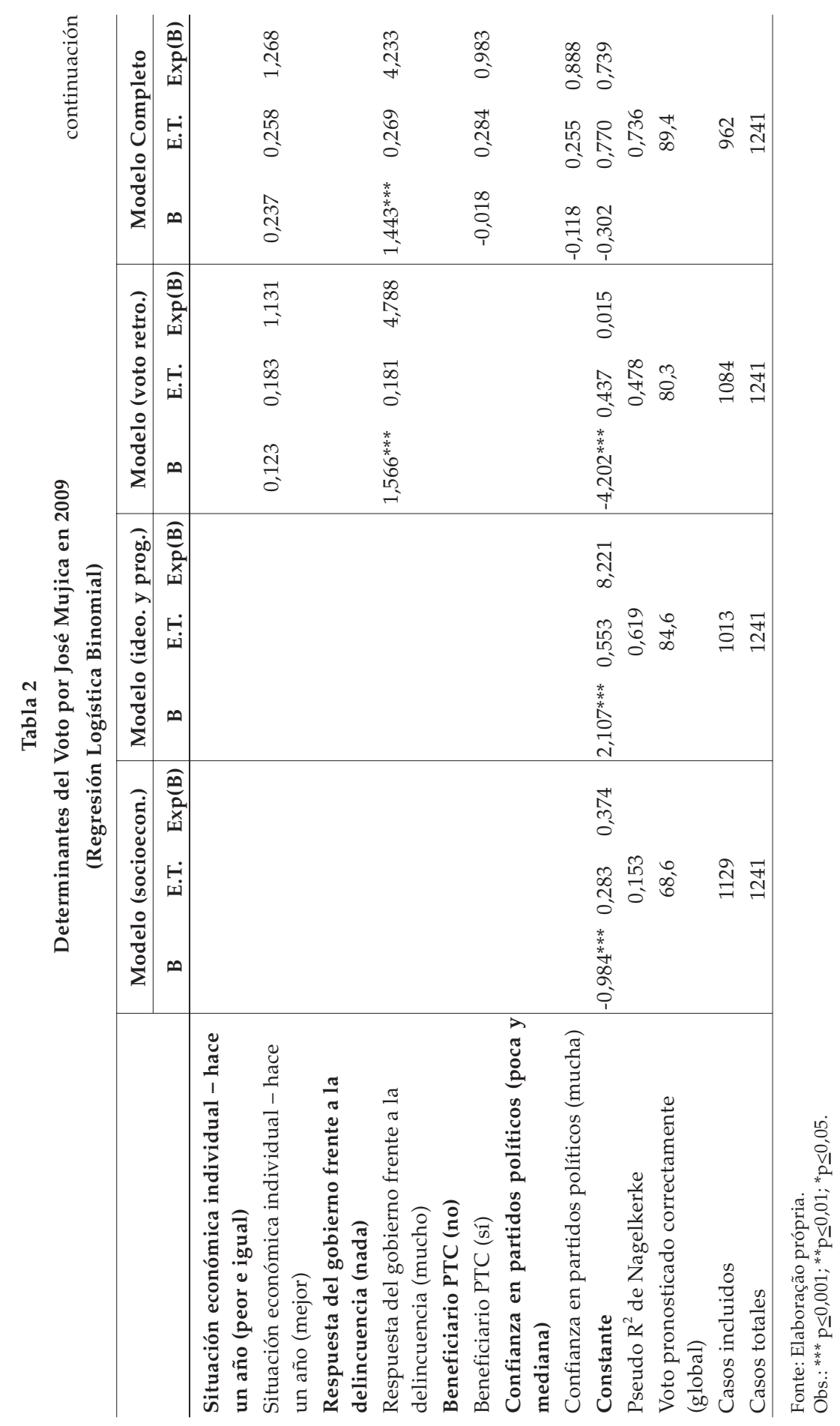

DADOS - Revista de Ciências Sociais, Rio de Janeiro, vol. 57, nํㅡ, 2014 
En segundo lugar, la religión aparece como otra de las variables estructurales que más impactan sobre la decisión de voto. La diferencia básica es entre católicos y los demás. Dentro de este segundo grupo, se encuentran tanto los que se declaran que no tienen ninguna religión (aunque creen en un "Ser Superior") como los agnósticos o ateos que no creen en Dios. Estos hallazgos coinciden con los de Selios y Vairo (2010).

Asimismo, los resultados son consistentes con las hipótesis sobre el peso de la ideología y los issues programáticos han sido corroborados. Estas variables diferencian claramente a los electores de la izquierda y de la derecha en Uruguay. Esto no es sorprendente, ya que el sistema de partidos uruguayo es uno de los más estables, con mayor proporción de personas que logran autoubicarse en el eje izquierda-derecha (Došek, 2011) y con el mayor grado de representación programática de la región, como muestran Mainwaring y sus colaboradores (2008) y Queirolo (2010).

De la misma manera, la evaluación retrospectiva positiva, tanto del desempeño del gobierno saliente de Vázquez como de la situación económica nacional, incrementa la probabilidad del voto por Mujica. Éstos reflejan probablemente los resultados económicos relativamente buenos y la alta aprobación presidencial en el período preelectoral. Estos resultados coinciden, en cierta medida, con los hallazgos de estudios que utilizaron otro tipo de datos de encuestas preelectorales (Selios y Vairo, 2010).

En ninguno de los dos casos las últimas dos variables incluidas en el modelo - el papel de los PTC y la confianza en los partidos políticos han diferenciado el voto a los gobernantes en el poder frente a la oposición. Es probable que la insignificancia de los PTC se deba a una menor envergadura de los programas (Cecchini y Madariaga, 2011), lo cual los diferencia del caso brasileño, y a la manera de cómo ha sido diseñada esta política pública.

\section{COMPARACIÓN DE LOS RESULTADOS A NIVEL DE PAÍSES}

Los cuatro modelos difieren en su capacidad de pronosticar el voto por los candidatos presidenciales en Bolivia y Uruguay en 2009. Para el caso boliviano, el modelo socioeconómico predice correctamente el $80,2 \%$ y, para Uruguay, solo el $68,6 \%$. El modelo socioeconómico predice, para el caso boliviano, correctamente el $80,2 \%$ y, para el caso uru- 
guayo, solo el $68,6 \%$ Asimismo, el pseudo $\mathrm{R}^{2}$ de Nagelkerke, que refleja el poder explicativo del modelo, la bondad del ajuste, alcanza, en el primer caso, $0,319 \mathrm{y}$, en el segundo, solo $0,153^{20}$.

Al agregar a este modelo básico la ideología y los issues programáticos en el caso boliviano, el voto pronosticado casi no se incrementa (de $80,2 \%$ a $81,5 \%$ ). No obstante, en el caso uruguayo, añadiendo las tres variables de este modelo, la variable dependiente sube de $68,6 \%$ al $84,6 \%$. Esto evidencia mucho mayor peso de las variables estructurales en Bolivia que las ideológicas y programáticas en el voto por Morales. Contrariamente, en Uruguay, las variables adicionales incrementan de manera significativa el porcentaje pronosticado del segundo modelo y, por tanto, dan cuenta del efecto de las divisiones de tipo estructural (religioso y urbano-rural), subsumiéndolas a las de naturaleza ideológica y programática.

El tercer modelo presenta una imagen relativamente diferente. En Bolivia, las cuatro variables del modelo de voto retrospectivo tienen más capacidad predictiva que los factores programáticos y el valor aumenta de $80,2 \%$ a $86,1 \%$. De la misma manera, la pseudo $R^{2}$ sube en una proporción mayor con este modelo (de 0,319 a 0,545 , comparado con 0,319 a 0,427 para el modelo de voto ideológico y programático). En Uruguay, al añadir las variables del voto retrospectivo, el porcentaje del voto pronosticado correctamente aumenta "sólo" a 80,3\% y la pseudo $\mathrm{R}^{2}$ a 0,478 . Por tanto, el modelo del voto retrospectivo parece aportar relativamente más en el caso de Bolivia que en Uruguay. En un trabajo reciente, Singer y Carlin (2013) sostienen que el voto económico retrospectivo es más fuerte entre los gobernantes en ejercicio que más tiempo hayan estado en el cargo. Esto podría explicar las diferencias entre Morales y Mujica. Sin embargo, los autores no responden por los casos donde el candidato es otra persona, diferente al candidato en el poder, pero pertenece al mismo partido, como ocurre con el caso uruguayo.

\section{COMPARACIÓN DE LOS MODELOS COMPLETOS: EL PESO DE LAS VARIABLES INDIVIDUALES}

El modelo completo que abarca todas las variables muestra la utilidad de los modelos de comportamiento electoral para el análisis de las determinantes de voto en Bolivia y Uruguay. El voto pronosticado en ambos casos es bastante alto, llegando a casi el $90 \%$ y los valores de la pseudo $R^{2}$ superan el 0,6: 0,612, en Bolivia, y 0,736, en Uruguay, dando 
cuenta de una alta bondad del ajuste, comparable con los niveles que alcanza en los trabajos sobre países occidentales (Nadeau et al., 2012).

Los modelos arrojan una serie de semejanzas y diferencias entre ambos países. Respecto de las primeras, las variables que incluyen el modelo de voto retrospectivo para las elecciones de 2009 (desempeño del gobierno saliente, situación económica y respuesta del gobierno frente al problema más grave del país) son significativas en ambos casos a nivel 0,01 de probabilidad. Los hallazgos no permiten diferenciar entre las dos izquierdas, ya que en ambos países los votantes muestran capacidad de evaluar la gestión del gobierno saliente a través del voto retrospectivo multidimensional.

Asimismo, los resultados no muestran la significatividad del voto egotrópico (evaluación de la situación económica individual) en ninguno de los dos países. Esto va parcialmente en contra de los hallazgos de Singer y Carlin (2013), quienes estudiando los países latinoamericanos, encuentran que está presente en los países con menores niveles de desarrollo. Sin embargo, aquí, en países con niveles disímiles de desarrollo el voto egotrópico no es significativo.

La variable que toma en cuenta el ser beneficiario de un Programa de Transferencias Condicionadas no distingue a los electores en Bolivia y en Uruguay y no es significativa en ninguno de los dos casos. Esto los diferencia de Venezuela, donde estos programas, a través de un diseño de movilización organizativa, generaron un clivaje de clases y repercutió directamente en el apoyo del partido oficialista (Handlin, 2013). Por su parte, en Brasil, el diseño ha sido tecnocrático y ha beneficiado al presidente Lula en su reelección, pero no a su partido político.

La diferencia entre los dos casos analizados radica en el peso de las variables temáticas e ideológicas y también en diferencias estructurales. Estas últimas se encuentran asociadas a la evolución social y política de cada país. En Bolivia, con la politización del latente clivaje étnico desde la mitad de la década de 1990 se visibilizó en términos de la competencia política esta división estructural que se ve claramente reflejada en los modelos de comportamiento electoral en las elecciones presidenciales de 2009 y también en los comicios anteriores tal como documenta Madrid (2008). Por el otro, parecería persistir el clivaje regional, pese a la mejora en los resultados electorales en la parte occidental del país por parte de Morales y su partido. Asimismo, estos clivajes parecen mucho más arraigados en la sociedad y resultan ser 
más importantes al momento de votar en un país étnico y regionalmente fragmentado. En Uruguay, la división rural-urbano (capitales-interior) responde a cómo surgió el Frente Amplio, y gana respaldo sobre todo en Montevideo ( $\mathrm{y}$ con el tiempo en otras grandes ciudades), y el clivaje religioso se debe a que Uruguay es tradicionalmente uno de los países con menor porcentaje de católicos y creyentes en América Latina.

Las variables ideológicas tienen mayor peso en Uruguay. La menor importancia de la ideología y los elementos programáticos en Bolivia se podría deber a dos motivos. Por un lado, una clara diferencia en la capacidad de autoubicarse en el eje ideológico entre los dos países: en Bolivia, más de una cuarta parte de la población no sabe identificarse, contrariamente a Uruguay, donde sólo el $8 \%$ no se ubicaba en la escala (Došek, 2011). Por el otro, la fuerte crisis de representación que vivió Bolivia, el colapso de los partidos tradicionales, los débiles vínculos de los partidos con los votantes y las organizaciones de la sociedad civil (Mayorga, 2005), dificulta la tarea de los electores de identificar la ideología y los principales issues de los partidos. Así, en los países con un sistema de partidos institucionalizado y una mayor tradición democrática (Uruguay), cabría esperar vínculos más ideológicos y programáticos ${ }^{21}$. Por el contrario, en países que vivieron una crisis de representación de los sistemas de partidos y un colapso de los partidos tradicionales, sumado al surgimiento de un liderazgo fuerte por fuera de estos partidos (Bolivia), el voto es menos ideológico y menos programático ${ }^{22}$.

\section{Clivajes, Ideología y Voto Retrospectivo: Claves para Comprender las Diferencias entre Países en la Región}

El estudio de los determinantes del voto - a través de tres ejes: factores estucturales, programáticos-ideológicos y de voto retrospectivo - no permite diferenciar a las supuestas dos izquierdas, dado que las realidades nacionales resultan más complejas y la presencia de distintos factores explicativos en los casos nacionales son transversales y no coinciden con la división en los dos grupos. Asimismo, el voto retrospectivo se evidencia en la mayoría de los casos aquí analizados y debatidos. Los hallazgos sobre las razones del voto y el peso de los respectivos factores, además, contrastan con otros países donde la izquierda llegó al poder.

Comenzando por las bases sociales, en Uruguay no hay diferencias en función de los ingresos de los votantes. Un hallazgo semejante es pre- 
sentado por Moncagatta y Safranoff (2013), sorprendentemente, para Ecuador, a diferencia de Venezuela, Bolivia y Argentina, donde las variables de ingreso y educación sí importan. Lupu (2010) sostiene que, a partir de 2006, Chávez recibe el apoyo de las clases medias, sin tenerlo entre los más pobres y los más ricos. Contrariamente, Handlin (2013) sostiene que hay un voto de clase debido a la movilización de este clivaje a través de los programas de protección social. Esto estaría de acuerdo con los resultados de Moncagatta y Safranoff (2013).

A esto, se suma la emergencia de nuevos clivajes - resultantes de la politización y latentes en la sociedad - y de temas políticos que, hasta el momento, no habían sido relevantes para la competencia política (Van Cott, 2005; Freidenberg, 2004 para Ecuador; Freidenberg y Domingo, 2006 para Ecuador y Bolivia; Torcal y Mainwaring, 2003 para Chile). Éstos responden a las particularidades nacionales y son representados, en el caso boliviano, por los clivajes étnicos y regionales que reflejan el ascenso de la cuestión indígena y la disputa por la autonomía regional, respectivamente, y que se han identificado también en diferentes formas en otros países como Perú (Raymond y Arce, 2013) o Chile (Torcal y Mainwaring, 2003).

Respecto de la importancia de la ideología, varios trabajos sobre Brasil (Rennó, 2007; Licio, Rennó y De Castro, 2009) sostienen que este factor no es importante para explicar el voto hacia Lula en 2006 frente a cualquier otro candidato en la primera vuelta. De la misma manera, Tagina (2012) no encuentra que la ideología sea un factor relevante en la primera elección de Cristina Fernández de Kirchner, en 2007, y Nadeau et al. (2012) tampoco lo hace para la intención de voto por Chávez en 2010. En este sentido, tanto Bolivia como Uruguay, pero también Chile (Morales, 2008), muestran una tendencia diferente, dado que la ideología pasa a ser una variable explicativa significativa.

Igualmente, a nivel regional, se notan importantes similitudes respecto al voto retrospectivo. En Argentina, el voto retrospectivo (económico) es más fuerte en 2007 que en 2003, en el caso de una "reelección partidista" con diferente candidato (como en el caso de Uruguay). En Brasil, en 2006, los trabajos también muestran la evaluación de la economía, los principales problemas del país y el desempeño del gobierno como factores que explican la reelección de Lula (Rennó, 2007). Para Chile, Morales (2008) mostró la importancia de la aprobación del gobierno de Lagos (2000-2006) para la elección de Bachelet. Nadeau et al. 
(2012) también resaltan la importancia de la evaluación de la situación económica, además de otros factores en el caso de la intención de voto hacia Chávez en 2010. Estos hallazgos van en línea con la relevancia del voto retrospectivo en Bolivia y Uruguay y con lo encontrado en las comparaciones regionales (Remmer, 1991; Ratto, 2013).

Por fin, como ya hemos discutido, varios trabajos han destacado el papel de los programas sociales en la reelección de Lula en 2006 (Rennó, 2007). Esto contrasta con los hallazgos para Bolivia y Uruguay donde el ser beneficiario de los programas de transferencias condicionadas no tiene efecto significativo sobre el voto. Esta comparación con otros países de la región que vivieron también la llegada de la izquierda en la última década da cuenta de la necesidad subrayada por Remmer (2012), Ratto (2013) o Moncagatta y Safranoff (2013) de analizar a los países por separado y ver cómo funcionan las tendencias regionales en los respectivos casos nacionales. De la misma manera que los trabajos sobre la llegada de la izquierda han encontrado explicaciones alternativas y a veces contradictorias, sus hallazgos sobre Brasil, Argentina o Venezuela reconocen la importancia de distintas explicaciones.

Uno de los pocos factores que está presente en la mayoría de los países es la evaluación retrospectiva del desempeño presidencial, tanto en general como de issues económicos u otros como la corrupción (Rennó, 2007). Esto está de acuerdo con los planteamientos de los trabajos que comparan las tendencias regionales, como los de Remmer (1991), Benton (2005) o Ratto (2013). Este factor parece ser el que más asemeja a los votantes de izquierda, sea esta radical o moderada, y confirma la ventaja de los candidatos del oficialismo (Bruno de Mesquita et al., 2003), sean estas las mismas personas o miembros del mismo partido.

El patrón es igual en Bolivia y Uruguay, de manera que la única variable que no se muestra significativa es la evaluación de la situación económica personal, lo que confirma tanto los hallazgos de Nadeau y Lewis-Beck (2001), en los países occidentales, como los de Benton (2005); Murillo, Oliveros y Vaishnav (2010) y Ratto (2013), en algunos países latinoamericanos. Estos resultados muestran que funciona la accountability vertical electoral (O'Donnell, 1996) y que los votantes premian a los candidatos oficialistas que tienen un buen desempeño en el gobierno, también en los casos de los gobiernos populistas y que, por tanto, la relación con estos presidentes no es solo no-racional o simbóli- 
ca, sino que los votantes realizan evaluaciones y los obligan a rendir cuentas ${ }^{23}$.

Los demás factores son condicionados por los contextos nacionales, con diferencias y similitudes entre los casos de las supuestas dos corrientes. Esto apuntaría a que el panorama regional es mucho más complicado, responde a las idiosincrasias y coyunturas nacionales, y los dos grupos no son suficientes para su clasificación.

\section{CONCLUSIONES}

Este artículo muestra que la investigación sobre el comportamiento electoral no contribuye a sostener que existen dos izquierdas en América Latina, sino que el panorama es mucho más complejo y responde, en gran medida, a coyunturas nacionales. Esta investigación se inició con la pretensión de identificar las razones de los electores de votar por la izquierda en dos casos representativos de las supuestas dos izquierdas y ver en qué medida los factores se asemejan o se diferencian en relación a los casos analizados (Bolivia y Uruguay). Tanto los hallazgos sobre los mismos como la comparación con otros estudios muestran que las diferencias entre las izquierdas contemporáneas son multidimensionales, con relevancia de diferentes factores explicativos de voto en ambos casos (factores estructurales, ideología, elementos programáticos, voto retrospectivo multidimensional o PTC) y que, al compararlas, las dos categorías planteadas por algunos autores no son suficientes. Esto se debe a las diversas trayectorias históricas, a las diferencias estructurales presentes entre los países y a los momentos de coyuntura en qué se analizan los respectivos casos. Esto avalaría la idea de que es muy difícil analizar los países latinoamericanos como un conjunto y que se necesita una aproximación más cualitativa para cada caso.

Se postula la necesidad de analizar los casos nacionales por separado (con métodos cuantitativos), con un diseño de investigación similar o de comparaciones cualitativas de $\mathrm{N}$ pequeña y con la intención de confirmar hasta qué punto se sostienen las tendencias regionales sobre la llegada de la izquierda al poder en América Latina (normalmente a través de diseños de tipo time series cross-section).

La discusión de los hallazgos de este artículo con la reciente literatura secundaria da cuenta de la importancia del voto retrospectivo en los 
países latinoamericanos, tanto en los casos populistas/radicales como en los más moderados. Esto va en línea con algunos de los recientes estudios tanto sobre el voto económico (Lewis-Beck y Ratto, 2013; Ratto, 2013; Singer, 2013; Singer y Carlin, 2013) como sobre la llegada de la izquierda al poder (Murillo, Oliveros y Vaishnav, 2010; Remmer, 2012). Sin embargo, este texto amplía el peso de los candidatos oficialistas ya que presenta que su relevancia se da tanto en los casos de reelección de la misma persona (tal como es normalmente concebida) como en los de un candidato del mismo partido. Esta es una variable que había sido omitida en otros estudios y muestra que los votantes latinoamericanos premian/castigan a sus representantes como en los países europeos. Asimismo, se sostiene que el voto retrospectivo no es solo económico, sino que puede tener que ver con otros temas salientes coyunturales.

Si bien esta investigación ha enfrentado al menos tres limitaciones, las mismas son desafíos a superar para avanzar en las respuestas necesarias a los dilemas planteados. Primero, no resulta factible observar el impacto de la campaña electoral, ya que esto requeriría de un estudio tipo panel. Segundo, resulta difícil determinar el papel de las personalidades de los candidatos, ya que los cuestionarios de LAPOP no suelen incluir una pregunta que permita operacionalizar esta variable independiente. Tercero, dichos cuestionarios no incluyen una pregunta sobre los vínculos de los votantes con los sindicatos u otras organizaciones sociales, variable que podría ser significativa, como han planteado Handlin y Berins Collier (2011) para el caso del Frente Amplio.

Queda para futuras investigaciones establecer si las diferencias aquí encontradas sobre el peso de la ideología y elementos programáticos en la explicación del voto están presentes en otros casos, dado que éstas se deben probablemente a las diferencias estructurales relacionadas con la evolución de los sistemas de partidos, sus crisis y distintos niveles de institucionalización. Un estudio muy interesante podría ser el análisis del caso brasileño y los gobiernos del PT que vivieron tanto la reelección del mismo candidato como de otros candidatos del mismo partido en las últimas dos elecciones y cuyo sistema de partidos se ha ido institucionalizando a lo largo del tiempo.

Asimismo, sería interesante repetir el mismo tipo de análisis en los países a lo largo del tiempo para observar, por ejemplo, hasta qué punto el MAS logra desarrollar un vínculo más ideológico, que podría conducir 


\section{Tomáš Došek}

a una mayor estabilidad en los patrones de representación ${ }^{24}$, o si la suerte de estos líderes depende solo de un contexto internacional favorable y de buenos resultados en la gestión y en si resuelven los problemas de los electores.

(Recebido para publicação em agosto de 2013)

(Reapresentado em março de 2014)

(Aprovado para publicação em abril de 2014) 


\section{NOTAS}

1. Existen algunas excepciones, como los trabajos de Samuels (2004), Madrid (2008 y 2011), Hawkins (2010), Lupu (2010), Handlin y Berrins Collier (2011) o Moncagatta y Safranoff (2013).

2. Una excepción son los trabajos dedicados a la reelección de Lula da Silva en Brasil, en 2006 (Hunter y Power, 2007; Rennó, 2007) o de Cristina Fernández de Kirchner (Tagina, 2012).

3. Es notable la carencia de trabajos de carácter comparado con datos de opinión pública. Esto se debe a la ausencia de encuestas poselectorales para toda la región y a algunos problemas metodológicos que implica la utilización de los datos del Latin American Public Opinion Project (LAPOP), como la cercanía temporal entre la encuesta y las elecciones o la existencia de preguntas adecuadas en los cuestionarios. Se agradece a LAPOP y sus mayores contribuyentes (USAID, PNUD, BID y la Universidad de Vanderbilt) por la posibilidad de utilizar sus bases de datos.

4. Un trabajo que se asemeja a éste es el de Lupu (2009), quien opta por una estrategia metodológica diferente, utilizando datos de LAPOP y modelos estadísticos multinivel.

5. Ver una estrategia parecida, de contraponer dos casos muy opuestos, en Luna y Filgueira (2009) para comparar Chile y Venezuela.

6. Los datos del LAPOP son utilizados de manera parecida a los estudios (post)electorales.

7. La posición ideológica de estos partidos, medida a partir de las autopercepciones de los diputados para el período 2009-2014, es la siguiente: MAS: 1,89 y PPB: 4,73 (para UN, no hay datos representativos) (PELA, 2010a).

8. La posición de los tres partidos en la escala izquierda-derecha, medida a partir de las autopercepciones de los diputados para el período 2009-2013, es la siguiente: FA: 2,95, PN: 5,88 y PC: 5,83 (PELA, 2010b).

9. Tabaré Vázquez ganó las elecciones presidenciales el 21 de octubre de 2004, obteniendo el $50,5 \%$ de votos en la primera vuelta. En 2009, Vázquez no pudo optar por la reelección, ya que la Constitución uruguaya impide dos mandatos presidenciales consecutivos.

10. La formulación de las preguntas está disponible en Moreno Morales et al. (2010) para Bolivia y Boidi y Queirolo (2010) para Uruguay.

11. Comúnmente se ha utilizado la regresión logística multinomial para el análisis de la primera vuelta de las elecciones presidenciales en la que hay más de dos candidatos (Rennó, 2007; Nicolau, 2007), dado que la variable dependiente no es dicotómica.

12. Ver Bartels (2012) para una revisión de las distintas tradiciones (modelos sociológico, psicosocial y de elección racional y el voto económico).

13. Véase, por ejemplo, Fiorina (1997), Freire (2001) o Anduiza y Bosch (2004).

14. Al incluir la variable de identificación partidista, su peso cancela el efecto de todas las demás, lo cual apunta a la posición de ser más bien una proxy del voto. Asimismo, esta variable está altamente correlacionada con la autoubicación ideológica. De la misma manera, estaban correlacionadas dos variables - respuestas a dos problemas más graves del país según la opinión pública. Por tanto, se optó por incluir sólo el pri- 


\section{Tomáš Došek}

mero. Las otras variables no están fuertemente correlacionadas, dando el Coeficiente de Pearson menor que 0,4 .

15. Los Programas de Transferencias Condicionadas (PTC) radican en el intercambio de pequeños montos monetarios a cambio del compromiso por parte de la familia de realizar una tarea, como por ejemplo, que los niños asistan a la escuela o de que visiten regularmente al médico (ver Cecchini y Madariaga, 2011).

16. El Plan de Asistencia Nacional a la Emergencia Social, conocido como Plan de Emergencia, fue seguido por el Plan de Equidad que ha sido percibido por la población "como si fuera" el Plan de Emergencia (Queirolo, 2010).

17. La pregunta del LAPOP incluye también las asignaciones familiares, las canastas alimenticias y la pensión a la vejez o invalidez.

18. Moreno Morales et al. (2010) dan cuenta de que los bolivianos incrementaron sus niveles de satisfacción con la democracia de manera significativa en los últimos años.

19. Morales tuvo que enfrentar un fuerte conflicto con los sectores indígenas por la construcción de una carretera que cruza el territorio indígena (Rossel Arce, 2012).

20. Los valores más altos de la pseudo $R^{2}$ implican que las variables independientes introducidas en el modelo mejoran la explicación de la variable dependiente.

21. Ver Nadeau et al. (2012) para Venezuela y Rennó (2007) para Brasil.

22. Nadeau et al. (2012) no encuentran significativa la ideología pero, en cambio, sí algunas cuestiones (dejaría issues) como inequidad, protección de derechos individuales o corrupción en el caso de la intención de voto por Chávez en 2010.

23. Los cuestionarios de LAPOP no contienen algunas preguntas que podrían medir esta dimensión y dar cuenta de vínculos alternativos - clientaleres y/o personalistas.

24. Esta observación no presupone ningún sesgo normativo respecto de qué tipo de vínculos son mejores o más democráticos para los ciudadanos o que los vínculos ideológicos y programáticos sean los únicos posibles. 


\section{REFERENCIAS BIBLIOGRÁFICAS}

ALBÓ, Xavier. (2007), “Bolivia: Avances y Tropezones Hacia un Nuevo País Plurinacional e Intercultural", in S. Martí i Puig (ed.), Pueblos Indígenas y Política en América Latina. Barcelona, Fundación CIDOB.

ALCÁNTARA SÁEZ, Manuel (ed). (2006), Políticos y Política en América Latina. Madrid, Siglo XXI.

ALCÁNTARA SÁEZ, Manuel y RIVAS, Cristina. (2007), “Las Dimensiones de la Polarización Partidista en América Latina”. Política y Gobierno, vol. XIV, no2, pp. 349-390.

ALPERT, Alexandra; CENTELLAS, Miguel y SINGER, Matthew. (2010), “The 2009 Presidential in Legislative Elections in Bolivia". Electoral Studies, vol. 29, no 4, pp. 757-761.

ANDUIZA, Eva y BOSCH, Agustí. (2004), Comportamiento Político y Electoral. Barcelona, Ariel.

BAKER, Andy y GREENE, Kenneth F. (2011), “The Latin American Left's Mandate. Free-Market Policies and Issue Voting in New Democracies". World Politics, vol. 63, no 1, pp. 43-77.

BARTELS, Larry. (2012), “The Study of Electoral Behavior", in J. E. Leighley (ed.), The Oxford Handbook of American Elections and Political Behavior. Oxford, Oxford University Press.

BEASLEY-MURRAY, Jon; CAMERON, Maxwell A. y HERSBERG, Eric. (2010), “Latin America's Left Turns: A Tour d'Horizon", in M. A. Cameron y E. Hershberg (eds.), Latin America's Left Turn. Politics, Policies, and Trajectories of Change. Boulder, Lynne Rienner Publisher.

BENTON, Allyson. (2005), “Dissatisfied Democrats or Retrospective Voters? Economic Hardship, Political Institutions, and Voting Behavior in Latin America". Comparative Political Studies, vol. 38, no 4, pp. 417-442.

BLANCO, Luisa y GRIER, Robin. (2013), “Explaining the Rise of the Left in Latin America". Latin American Research Review, vol. 48, no 1, pp. 68-90.

BOIDI, María Fernanda y QUEIROLO, María del Rosario. (2010), Cultura Política de la Democracia en Uruguay, 2010. Consolidación Democrática en las Américas en Tiempos Difíciles. Nashville, Vanderbilt University.

BRUNO DE MESQUITA, Bruce et al. (2003), The Logic of Political Survival. Cambridge, Massachusetts Institute of Technology.

BUQUET, Daniel y DE ARMAS, Gustavo. (2004), “La Evolución Electoral de la Izquierda: Crecimiento Demográfico y Moderación Ideológica", in J. Lanzaro (coord.), La Izquierda Uruguaya entre la Oposición y el Gobierno. Montevideo, Editorial Fin de Siglo, Instituto de Ciencia Política.

BUQUET, Daniel y PIÑEIRO, Rafael. (2011), “Del Cambio a la Continuidad: las Elecciones de 2009", in M. Alcántara Sáez y M. L. Tagina (eds.), América Latina: Política y Elecciones del Bicentenario (2009-2010). Madrid, Centro de Estudios Políticos y Constitucionales. 


\section{Tomáš Došek}

CAMERON, Maxwell A. y HERSHBERG, Eric (eds.). (2010), Latin America's Left Turn. Politics, Policies, and Trajectories of Change. Boulder, Lynne Rienner Publisher.

CANZANI, Agustín. (2010), “Un País Suavemente Ondulado. Resultados y Desafíos de las Elecciones Uruguayas de 2009". Nueva Sociedad, no 225, pp. 18-30.

CARDOSO, Fernando Henrique. (2006), “Izquierda y Populismo en América Latina”. La Voz del Interior. Córdoba, Argentina, 8 de junio.

CASTAÑEDA, Jorge. (2006), “Latin America's Left Turn”. Foreing Affairs, vol. 85, no 3, pp. 28-43.

y MORALES, Marco A. (eds.). (2008), Leftovers. Tales of the Latin-American Left. London, Routledge.

CECCHINI, Simone y MADARIAGA, Aldo. (2011), Programas de Transferencias Condicionadas. Balance de la Experiencia Reciente en América Latina y el Caribe. Santiago de Chile, CEPAL.

CEPAL (Comisión Económica para América Latina). (2010), Panorama Social de América Latina 2010. Santiago de Chile, CEPAL.

CLEARY, Matthew R. (2006), "A 'left Turn' in Latin America? Explaining the Left's Resurgence". Journal of Democracy, vol. 17, no 4, pp. 35-49.

CÓRDOVA, Eduardo. (2010), “Movimientos Sociales en Bolivia. Acción Colectiva y Democracia en Tiempos de Cambio (1990-2009)", in M. Tanaka y F. Jácome (eds.), Desafíos de la Gobernabilidad Democrática. Reformas Político-Institucionales y Movimientos Sociales en la Región Andina. Lima, IEP, IDRC-CRDI, INVESP.

DALTON, Russell J. y ANDERSON, Christopher J. (2011), “Citizens, Context, and Choice", in R. J. Dalton y C. J. Anderson (eds.), Citizens, Context, and Choice. How Context Shapes Citizens' Electoral Choices. Oxford, Oxford University Press.

DE ARMAS, Gustavo. (2009), "Debilitamiento del Efecto Demográfico y Consolidación de un Nuevo Sistema de Partidos: Evidencia de las Elecciones de 2009 en Uruguay". Revista Uruguaya de Ciencia Política, vol. 18, no 1, pp. 41-63.

DEBS, Alexandre y HELMKE, Gretchen. (2010), “Inequality under Democracy: Explaining the Left Decade in Latin America". Quarterly Journal of Political Science, vol. 5, no 3, pp. 209-241.

DOŠEK, Tomáš. (2011), “ Do Left and Right Differentiate Citizens and Politicians in Latin America?". Boletin \#3. Programa de Naciones Unidas para el Desarrollo e Instituto de Iberoamérica. Disponible en línea: http://www.vanderbilt.edu/lapop/insights/ 062011.PNUD_PELA_Report3.pdf.

FIORINA, Morris P. (1997), "Voting Behavior", in D. E. Mueller (ed.), Perspectives on Public Choice: A Handbook. Cambridge, Cambridge University Press.

FREIDENBERG, Flavia. (2004), "Fracturas Sociales y Sistemas de Partidos en Ecuador: La Traducción Política de un Cleavage Étnico", in S. Martí i Puig (ed.), Etnicidad, Autonomía y Gobernabilidad en América Latina. Salamanca, Ediciones Universidad de Salamanca.

y DOMINGO, Pilar. (2006), “¿Por qué se Mueve la Gente? Movimientos Indígenas y Nuevas Formas de Representación Política en Bolivia y Ecuador". Ponencia pre- 
sentada en XXVI Meeting of Latin American Studies Association. San Juan, Puerto Rico, 16-18 de marzo.

FREIRE, André. (2001), Modelos do Comportamento Eleitoral: Uma Breve Introdução Crítica. Oeiras, Celta Editora.

GARCÉ, Adolfo y YAFFÉ, Jaime. (2006), “La Izquierda Uruguaya (1971-2004): Ideología, Estrategia y Programa". América Latina Hoy, vol. 44, pp. 87-114.

GERRING, John. (2007), Case Study Research: Principles and Practices. Cambridge, Cambridge University Press.

GONZÁLEZ, Luis E. (2010), “La Estabilización del Sistema de Partidos Uruguayo, 1999-2009", in L. E. González et al., El Voto en Uruguay 2009/2010. Montevideo, Universidad Católica Damaso A. Larrañaga, Konrad Adenauer Stiftung.

GRAY MOLINA, George. (2010), “The Challenge of Progresive Change under Evo Morales", in K. Weyland, R. Madrid y W. Hunter (eds.), Leftist Governments in Latin America: Successes and Shortcomings. Cambridge, Cambridge University Press.

HANDLIN, Samuel. (2013), "Social Protection and the Politicization of Class Cleavages during Latin America's Left Turn”. Comparative Political Studies, vol. 46, no 12, pp. 1582-1609.

HANDLIN, Samuel y BERINS COLLIER, Ruth. (2011), "The Diversity of Left Party Linkages and Competitive Advantages", in S. Levitsky y K. Roberts (eds.), The Resurgence of the Left in Latin America. Baltimore, The Johns Hopkins University Press.

HARO GONZÁLEZ, Ana. (2011), “Bolivia: las Elecciones de 2009. Tomando Posiciones para el Desarrollo de la Constitución", in M. Alcántara Sáez y M. L. Tagina (eds.), América Latina: Política y Elecciones del Bicentenario (2009-2010). Madrid, Centro de Estudios Políticos y Constitucionales.

HAWKINS, Kirk A. (2010), “Who Mobilizes? Participatory Democracy in Chávez's Bolivarian Revolution". Latin American Politics and Society, vol. 52, no 3, pp. 31-52.

HUNTER, Wendy y POWER, Timothy. (2007), “Rewarding Lula: Executive Power, Social Policy, and the Brazilian Elections of 2006". Latin American Politics and Society, vol. 49, no 1, pp. 1-30.

KITSCHELT, Herbert et al. (2010), Latin American Party Systems. Cambridge, Cambridge University Press.

LANZARO, Jorge. (2004), “La Izquierda se Acerca a los Uruguayos y los Uruguayos se Acercan a la Izquierda. Claves de Desarrollo del Frente Amplio", in J. Lanzaro (coord.), La Izquierda Uruguaya entre la Oposición y el Gobierno. Montevideo, Editorial Fin de Siglo, Instituto de Ciencia Política.

(2006), “La Tercera Ola de las Izquierdas Latinoamericanas. Entre el Populismo y la Social Democracia", in P. Pérez Herrero (ed.), Las Izquierdas Latinoamericanas y el Gobierno: Experiencias y Desafíos. Madrid, Editorial Pablo Iglesias.

(2008), "La Social Democracia Criolla". Nueva Sociedad, no 217, pp. 10-22.

(2011), "Uruguay: A Social Democratic Government in Latin America", in S. Levitsky y K. Roberts (eds.), The Resurgence of the Left in Latin America. Baltimore, The Johns Hopkins University Press. 


\section{Tomáš Došek}

LAPOP (Latin American Public Opinion Project). (2010a), Barómetro de las Américas, Bolivia, 2010. Disponible en línea: www.vanderbilt.edu/lapop.

(2010b), Barómetro de las Américas, Uruguay, 2010. Latin American Public Opinion Project (LAPOP). Disponible en línea: www.vanderbilt.edu/lapop.

LAZARSFELD, P. F.; BERELSON, Bernard y GAUDET, Hazel. (1944), The People's Choice. New York, Duell, Sloan and Pearce.

LEIRAS, Marcelo. (2007), "Latin America's Electoral Turn: Left, Right, and Wrong”. Constellations, vol. 14, no 3, 398-408.

LEVITSKY, Steven y ROBERTS, Kenneth (eds.). (2011), The Resurgence of the Left in Latin America. Baltimore, The Johns Hopkins University Press.

LEWIS-BECK, Michael y RATTO, María Celeste. (2013), “Economic Voting in Latin America: A General Model". Electoral Studies, vol. 32, no 3, pp. 489-493.

LICIO, Elaine Cristina, RENNÓ, Lucio y DE CASTRO, Henrique Carlos de O. (2009), "Bolsa Família e Voto na Eleição Presidencial de 2006. Em Busca do Elo Perdido". Opinão Pública, vol. 15, no 1, pp. 31-54.

LORA, Eduardo y OLIVERA, Mauricio. (2005), "The Electoral Consequences of the Washington Consensus". Economía, vol. 5, no 2, pp. 1-61.

LUNA, Juan Pablo. (2010), “The Left Turns: Why They Happened and How They Compare", in M. A. Cameron y E. Hershberg (eds.), Latin America's Left Turn. Politics, Policies, and Trajectories of Change. Boulder, Lynne Rienner Publisher.

y FILGUEIRA, Fernando. (2009), "The Left Turns as Multiple Paradigmatic Crises". Third World Quarterly, vol. 30, no 2, pp. 371-395.

LUPU, Noam. (2009), "Electoral Bases of Leftist Presidents in Latin America”. Disponible en línea: http:/ / www.udesa.edu.ar/files/UAHumanidades/EVENTOS/Paper NoamLupu100809.pdf

(2010), "Who Votes for Chavismo? Class Voting in Hugo Chávez's Venezuela". Latin American Research Review, vol. 45, no 1, pp. 7-32.

LYNCH, Nicolas. (2007), "What the 'Left' Means in Latin American Now". Constellations, vol, 14, no 3, pp. 373-383.

MADRID, Raúl. (2008), "The Rise of Ethnopopulism in Latin America". World Politics, vol. 60 , no 3, pp. 475-508.

MADRID, Raúl. (2011), "Ethnic Proximity and Ethnic Voting in Peru". Journal of Latin American Studies, vol. 43, no 2, pp. 267-297.

MAINWARING, Scott y SCULLY, Timothy (eds.). (1995), Building Democratic Institutions. Stanford, Stanford University Press.

MAINWARING, Scott; BEJARANO, Ana M. y PIZARRO, Eduardo. (2008), “La Crisis de la Representación Democrática en los Países Andinos: Un Panorama General", in S. Mainwaring, A. M. Bejarano y E. Pizarro (eds.), La Crisis de Representación Democrática en los Países Andinos. Bogotá, Norma.

MAYORGA, Fernando. (2009), “El Gobierno de Evo Morales: Nacionalismo e Indigenismo en Tiempos de Cambio", in M. Tanaka (ed.), La Nueva Coyuntura Crítica en los Países Andinos. Lima, IEP e IDEA International. 
(2010), "Bolivia: El Azaroso Camino de la Reforma Política", in M. Tanaka y F. Jácome (eds.), Desafíos de la Gobernabilidad Democrática. Reformas Político-Institucionales y Movimientos Sociales en la Región Andina. Lima, IEP, IDRC-CRDI, INVESP.

MAYORGA, René Antonio. (2005), "Bolivia's Democracy at the Crossroads", in F. Hagopian y S. Mainwaring (eds.), The Third Wave of Democratization in Latin America: Advances and Setbacks. Cambridge, Cambridge University Press.

MONCAGATTA, Paolo y SAFRANOFF, Ana. (2013), “¿Quién Apoya a la Izquierda ‘Populista' Latinoamericana?". Revista Mexicana de Análisis Político y Administración Pública, vol. 2, no 1, pp. 29-45.

MORALES, Mauricio. (2008), “La Primera Mujer Presidenta de Chile: ¿Qué Explicó el Triunfo de Michelle Bachelet en las Elecciones de 2005-2006?". Latin American Research Review, vol. 43, no 1, pp. 7-32.

MOREIRA, Constanza. (2010), “Clase, Voto e Ideología: Desempeño Electoral del Frente Amplio en el Ciclo Electoral 2009-2010", in D. Buquet y N. Johnson (coords.), Del Cambio a la Continuidad, Ciclo Electoral 2009-2010 en Uruguay. Montevideo, Fin de Siglo, ICP, CLACSO.

MORENO MORALES, Daniel et al. (2010), Cultura Política de la Democracia en Bolivia, 2010. Consolidación Democrática en las Américas en Tiempos Difíciles. Nashville, Vanderbilt University.

MURILLO, María Victoria; OLIVEROS, Virginia y VAISHNAV, Milan. (2010), “Electoral Revolution or Democratic Alternation?", Latin American Research Review, vol. 45, no3, pp. 87-114.

NADEAU, Richard y LEWIS-BECK, Michael S. (2001), "National Economic Voting in U.S. Presidential Elections”. Journal of Politics, vol. 63, no 1, pp. 159-181.

NADEAU, Richard et al. (2012), The Chavez Vote and "El Hombre Económico". Ponencia presentada en el 22 Congreso Internacional de Ciencia Política, Madrid, España, 8-12 de julio.

NICOLAU, Jairo. (2007), “An Analysis of the 2002 Presidential Elections Using Logistic Regression". Brazilian Political Science Review, vol. 1, no 1, pp. 125-135.

O’DONNELL, Guillermo. (1996), “Otra Institucionalización”. Política y Gobierno, vol. III, no 2, pp. 219-244.

PANIZZA, Francisco. (2005), "Unarmed Utopia Revisited: The Resurgence of Left-of-Centre Politics in Latin America". Political Studies, vol. 53, no 4, pp. 716-734.

PARAMIO, Ludolfo. (2006), "Giro a la Izquierda y Regreso del Populismo". Nueva Sociedad, no 205, pp. 62-74.

PAYNE, J. Mark; ZOVATTO, Daniel y MATEO DÍAZ, Mercedes. (2006), La Política Importa. Democracia y Desarrollo en América Latina. Washington, D.C., BID, IDEA International.

PELA (Proyecto Élites Parlamentarias en América Latina). (2010a), Encuesta a Representantes Bolivianos 2010-2014, Estudio 81: Bolivia. Universidad de Salamanca. Disponible en línea: http:/ / americo.usal.es/oir/elites/eliteca.htm 


\section{Tomáš Došek}

.(2010b), Uruguay. Encuesta a Diputados Uruguayos 2010, Estudio 76: Uruguay. Universidad de Salamanca. Disponible en línea: http://americo.usal.es/oir/elites/eliteca.htm

PEREIRA DA SILVA, Fabricio. (2010), “Esquerdas Latino-Americanas: Uma Tipologia é Possível?". OIKOS, vol. 9, no 2, pp. 121-140.

PETKOFF, Teodoro. (2005), “Las Dos Izquierdas”. Nueva Sociedad, no 197, pp. 114-128.

QUEIROLO, Rosario. (2008), “Interpretando el Voto de Izquierda en América Latina: ¿Riesgo u Oportunidad?", in M. Seligson (ed.), Desafíos para la Democracia en Latinoamérica y el Caribe: Evidencia desde el Barómetro de las Américas 2006-2007. Nashville, Vanderbilt University.

QUEIROLO, Rosario. (2010), "El Rol de los Programas de Transferencias Monetarias en la Reeleción del Frente Amplio en 2009", in D. Buquet y N. Johnson (coords.), Del Cambio a la Continuidad, Ciclo Electoral 2009-2010 en Uruguay. Montevideo, Fin de Siglo, ICP, CLACSO.

RAMíREZ GALLEGOS, Franklin. (2006), “Mucho Más que dos Izquierdas”. Nueva Sociedad, no 205, pp. 31-44.

RATTO, María Celeste. (2013), “Accountability y Voto Económico en América Latina: Un Estudio de las Pautas de Comportamiento Electoral entre 1996 y 2004". Revista Mexicana de Análisis Político y Administración Pública, vol. 2, no 1, pp. 49-80.

RAYMOND, Christopher y ARCE, Moisés. (2013), "The Politicization of Indigenous Identities in Peru". Party Politics, vol. 19, no 4, pp. 555-576.

REMMER, Karen. (1991), "The Political Impact of Economic Crisis in Latin America in the 1980s". American Political Science Review, vol. 85, no 3, pp. 777-800.

(2012), “The Rise of Leftist-Populist Governance in Latin America: The Roots of Electoral Change". Comparative Political Studies, vol. 45, no 8, pp. 947-972.

RENNÓ, Lucio. (2007), “Escândalos e Voto: As Eleições Presidenciais Brasileiras de 2006". Opinão Pública, vol. 13, no 2, pp. 260-282.

RODRÍGUEZ GARAVITO, César A. y BARRETT, Patrick S. (2005), “¿La Utopía Revivida? Introducción al Estudio de la Nueva Izquierda Latinoamericana", in C. A. Rodríguez Garavito, P. S. Barret y D. Chavez (eds.), La Nueva Izquierda en América Latina. Sus Orígenes y Trayectoria Futura. Bogotá, Norma.

RODRÍGUEZ GARAVITO, César A., BARRETT, Patrick S. y CHAVEZ, Daniel (eds.). (2005), La Nueva Izquierda en América Latina. Sus Orígenes y Trayectoria Futura. Bogotá, Norma.

ROMERO BALLIVIÁN, Salvador. (2007), “La Elección Presidencial del 18 de Diciembre de 2005 en Bolivia", in S. R. Ballivián (comp.), Atlas Electoral Latinoamericano. La Paz, Corte Nacional Electoral.

ROSSEL ARCE, Pablo. (2012), “2011: ¿El Parteaguas del Evismo? Bolivia Después del Conflicto del Tipnis". Nueva Sociedad, no 237, pp. 4-16.

SAMUELS, David. (2004), “Las Bases del PT: Ideología versus Personalismo en su Apoyo Electoral". América Latina Hoy, vol. 37, pp. 63-80. 
SELIOS, Lucía y VAIRO, Daniela. (2010), “Desde las Lealtades Partidarias a la Accountability Electoral: Análisis de las Determinantes del Voto y la Reciente Evolución Electoral en Uruguay", in D. Buquet y N. Johnson (coords.), Del Cambio a la Continuidad, Ciclo Electoral 2009-2010 en Uruguay. Montevideo, Fin de Siglo, ICP, CLACSO.

SINGER, Matthew. (2007), “The Presidential and Parliamentary Elections in Bolivia, December 2005". Electoral Studies, vol. 26, № 1, pp. 200-205.

. (2013), "Economic Voting in an Era of (Non)Crisis: The Changing Electoral Agenda in Latin America 1982-2010". Comparative Politics, vol. 45, no 2, pp. 169-185.

_ y CARLIN, Ryan. (2013), "Context Counts: The Election Cycle, Development, and the Nature of Economic Voting". Journal of Politics, vol. 75, no 3, pp. 730-742.

TAGINA, María Laura. (2012), “Factores Contextuales, Predisposiciones de Largo Plazo y Accountability Electoral en Argentina en Tiempos del Kirchnerismo". Política y Gobierno, vol. XIX, no 2, pp. 343-375.

TORCAL, Mariano y MAINWARING, Scott. (2003), "The Political Recrafting of Social Bases of Party Competition: Chile, 1973-95". British Journal of Political Science, vol. 33, no 1, pp. 55-84.

VAN COTT, Donna Lee. (2005), From Movements to Parties in Latin America. The Evolution of Ethnic Politics. Cambridge, Cambridge University Press.

VARGAS DEL CARPIO RIBERT, Oscar. (2011), “Voto, Ocupación y Clase Media: El Apoyo a Evo Morales". Revista Ciencia y Cultura, no 26, pp. 83-91.

WALKER, Ignacio. (2008), “The Three Lefts of Latin America”. Dissent, vol. 55, no 4, pp. $5-12$.

WEYLAND, Kurt. (2010), "The Performance of Leftist Governments in Latin America", in K. Weyland, R. Madrid y W. Hunter (eds.), Leftist Governments in Latin America: Successes and Shortcomings. Cambridge, Cambridge University Press.

. (2013), "The Threat from Populist Left". Journal of Democracy, vol. 24, no 3, pp. $18-32$.

; MADRID, Raúl y HUNTER, Wendy (eds.). (2010), Leftist Governments in Latin America: Successes and Shortcomings. Cambridge, Cambridge University Press. 


\section{Tomáš Došek}

\section{RESUMO}

Por que as Pessoas Votam na Esquerda? Clivagens, Ideologia e Voto Retrospectivo na Bolívia e no Uruguai em Perspectiva Comparada

O objetivo deste artigo é duplo: por um lado, explicar as razões do voto dos cidadãos bolivianos e uruguaios, respectivamente, a Evo Morales e José Mujica nas eleições presidenciais de 2009; e, por outro lado, avaliar em que medida os determinantes do voto permitem diferenciar as supostas "duas esquerdas" na América Latina. Utilizando dados de pesquisas de opinião pública para os dois casos representativos, o texto mostra como as razões são diferentes, já que no Uruguai pesa relativamente mais a ideologia e os elementos programáticos, enquanto na Bolívia predomina o voto retrospectivo, ambos atravessados por diferentes clivagens estruturais. Após discutir os resultados com a literatura secundária sobre outros casos sul-americanos, argumenta-se que a classificação das duas esquerdas não se sustenta a partir da análise dos determinantes do voto. Metodologicamente, utiliza-se a análise de regressão logística binomial e a comparação de uma série de modelos estatísticos.

Palavras-chave: esquerda; comportamento eleitoral; Evo Morales; José Mujica; voto retrospectivo multidimensional; ideologia; voto programático

\section{ABSTRACT \\ Why do People Vote for the Left? Cleavages, Ideology and Retrospective Votes in Bolivia and Uruguay in Comparative Perspective}

The aim of this article is twofold: on one hand, to explain why Bolivian and Uruguayan citizens casted ballots for Evo Morales and José Mujica, respectively, in the 2009 presidential elections, and, on the other hand, assess the extent to which factors that determine voting can outline a purported distinction between the "two lefts" in Latin America. Using public opinion poll data concerning these two representative cases, this article shows that voter motivations were indeed different. In Uruguay, ideology and programmatic issues were more important, while in Bolivia the retrospective voting contributes more to explain the vote for the left. In both cases, the voting patterns are also structured by social and geographic cleavages. Yet, after discussing the results in light of the secondary literature on other South American cases, it is argued that the classification in terms of "two lefts" does not hold considering the analysis of vote determinants. In methodological terms, the article uses binomial logistic regression and compares a series of statistical models.

Keywords: left; electoral behavior; Evo Morales; José Mujica; retrospective voting; ideology; issue voting 


\section{RÉSUMÉ}

Pourquoi les Gens Votent-ils à Gauche? Clivages, Idéologie et Vote Rétrospectif dans une Comparaison entre la Bolivie et l'Uruguay

Dans cet article, on cherche à expliquer non seulement comment ont voté, aux élections présidentielles de 2009, les citoyens boliviens et uruguayens pour Evo Morales et José Mujica, respectivement, mais aussi à estimer dans quelle mesure les facteurs déterminants du vote permettent de distinguer "deux gauches" présumées en Amérique Latine. On s'est servi de données de sondages d'opinion pour les deux cas, d'après lesquelles on peut relever que, pour l’Uruguay, le plus déterminant est l'idéologie et les éléments des programmes, tandis que, en Bolivie, le vote rétrospectif domine, bien que tous les deux soient soumis à divers clivages structuraux. Après rapprochement de ces résultats avec la littérature d'autres cas sud-américains, on soutient que la classification des deux gauches ne s'appuie pas sur l'examen des déterminants du vote. Quant à la méthodologie, on s'est servi de l'analyse de régression logistique binomiale et de la comparaison d'une série de modèles statistiques.

Mots-clés: gauche; comportement électoral; Evo Morales; José Mujica; vote rétrospectif multidimensionel; idéologie; vote sur programme

\section{RESUMEN}

¿Por qué la Gente Vota a la Izquierda? Clivajes, Ideología y Voto Retrospectivo en Bolivia y Uruguay en Perspectiva Comparada

El objetivo de este artículo es explicar las razones del voto de los ciudadanos hacia Evo Morales y José Mujica en las elecciones presidenciales de 2009 y evaluar en qué medida los determinantes del voto permiten distinguir las supuestas "dos izquierdas" en América Latina. Utilizando datos de encuestas de opinión pública para los dos casos representativos este trabajo muestra cómo las razones son diferentes, ya que en Uruguay pesa relativamente más la ideología y los elementos programáticos y en Bolivia más el voto retrospectivo, cruzado cada uno por distintos clivajes estructurales. Discutiendo los resultados con la literatura secundaria sobre los demás casos sudamericanos, se argumenta que la clásica clasificación en dos izquierdas no se sostiene a partir del análisis de los determinantes del voto. Metodológicamente, se recurre al análisis de regresión logística binomial y a la comparación de una serie de modelos estadísticos.

Palabras clave: izquierda; comportamiento electoral; Morales; Mujica; voto retrospectivo multidimensional; ideología; voto programático 
